\title{
7 \\ Derecho de las Sociedades Cooperativas en Euskadi: Un análisis sobre su estructura orgánica y la política cooperativa de los últimos ejercicios
}

\author{
Elena Atienza Mazías / José Andrés Merino Mar I \\ E. Guillermo Ruiz de Huydobro y de Las Muñecas \\ Universidad de Deusto
}

Sumario: Breve comentario por los autores-Origen histórico de las cooperativas. - La Competencia en materia de Derecho cooperativo. Marco constitucional y problema legislativo.--Ley 1/2000, de 29 de junio, de modificación de la Ley de Cooperativas de Euskadi. I. Introducción. I.1. ¿Qué supuso la Ley de Cooperativas de Euskadi 4/1993 de 24 de junio? II. Fundamentos de la reforma. II.1. Los principales ámbitos sustantivos que aborda la actual reforma son: II.2. El período de gestación de la Ley. II.3. Más posibilidades de crear pequeñas Cooperativas: II.4. Hacia una mayor cooperativización: II.5. Mejora del régimen del capital: II.6. Cobertura jurídica para los Grupos Cooperativos: II.7. Evitar discriminaciones al socio trabajador: III. Novedades introducidas por la ley $1 / 2000$ de 29 de junio respecto articulado de la Ley 4/1993, de 24 de junio: III.1. Novedades específicas. III.2. Otras novedades. - El régimen jurídico de los socios.I. El Socio. II. Número de socios. III. Clases de socios. III.1. Socios activos o usuarios. III.2. Socios colaboradores. III.3. Socios de trabajo. III.4. Socios inactivos o no usuarios. III.5. Socios de duración determinada. IV. La admisión. V. Obligaciones de los socios. VI. Derechos de los socios. VI.1. Derecho y ejercicio. VI.2. El derecho de información. VI.3. Límites y garantías del derecho de información. VII. Baja de los socios. VII.1. Tipos de bajas. VII.2. Calificación. VII.3. Recursos. VIII. Normas de disciplina social. VIII.1. Tipificación. VIII.2. Tipos de sanción. VIII.3. Prescripción. VIII.4. Procedimiento y recursos. VIII.5. La expulsión.-La Asamblea General. I. Concepto y competencias. II. Clases de asambleas generales. III. Convocatoria de la asamblea general. III.1. Órgano facultado para convocar la asamblea. III.2. Forma de convocar la asamblea. III.3. Publicidad de la convocatoria. III.4. Contenido de la convocatoria. IV. Funcionamiento de la asamblea general. VI.1. Lugar de celebración de la asamblea general. IV.2. Quórum de constitución de la asamblea general. IV.3. Derecho de asistencia. IV.4. Desarrollo de la asamblea general. V. Derecho de voto. VI. El régimen de mayorías. VII. Acta de la asamblea. VIII. La asamblea de delegados. IX. Impugnación 
de acuerdos de la asamblea general._Los administradores. I. Concepto. II. Naturaleza de los miembros. III. Nombramiento de los administradores, duración del cargo y cese. IV. Composición y renovación del consejo rector. V. Remuneración. VI. Funcionamiento del Consejo rector. VII. Responsabilidad. VIII. Impugnación de acuerdos.—La Comisión de vigilancia. I. Composición, mandato y nombramiento. II. Facultades de información. III. Ambito de actuación.IV. Competencias y funcionamiento.-El Consejo Social.-El Comité de recursos.-Consejo Superior de Cooperativas del País Vasco. I. Introducción. II. Esbozo Histórico. III. ¿Qué supuso la instauración del Consejo Superior de cooperativas? IV. Notas a destacar. V. Naturaleza. VI. Composición. VII. Funciones. VIII. ¿Cómo se financia?-Dirección de Economía Social del Gobierno Vasco (actuación sobre Cooperativas y Sociedades, anónimas y limitadas, Laborales). I. Tareas que desarrolla la Dirección. I.1. Fomento. I.2. La vertiente jurídica. I.3.Dotación de recursos económicos y personales.-Retos: Nuevas Cooperativas (Comparación 2002-2003). I. Líneas de actuación del ejercicio 2002. II. Líneas de Actuación ejercicio 2003. III. Plan Estratégico 2003-2005._Conclusión: Cooperativismo con futuro y de futuro.-Bibliografía.

\section{BREVE COMENTARIO POR LOS AUTORES}

Ante todo debemos señalar que nuestro objetivo, en un inicio, era efectivamente hacer un simple análisis de las modificaciones que nuestra legislación de cooperativas ha experimentado a lo largo del tiempo, haciendo especial hincapié en los cambios más recientes. Sin embargo, conforme profundizábamos en nuestra labor sentimos la necesidad de ampliar la temática. Con ese objetivo la documentación empleada varió para permitirnos apreciar, no ya sólo el plano jurídicocooperativo que con tanta profundidad nos han descrito GADEA y DIVAR, sino también la manifestación político-cooperativa que han puesto de manifiesto BUITRÓN ANDRADE e ISPIZUA.

Con el objeto de aportar más un visión unificada del mundo cooperativo vasco que una nueva versión o propuesta hemos redactado un comentario exhaustivo, quizá no del todo sistemático y en ocasiones crítico con la estructura de la ley vasca en lo que se refiere a los órganos de las sociedades cooperativas.

Atentamente los autores 


\section{ORIGEN HISTÓRICO DE LAS COOPERATIVAS}

Las cooperativas surgieron como institución técnico-económica en la 2. ${ }^{a}$ mitad del siglo XIX aunque existen precedentes desde finales del s. XVIII de sociedades económicas de carácter comunitario o cooperativo.

Se desarrollan en Europa cuando se produce la 1. ${ }^{a}$ industrialización a mediados del $\mathrm{s}$. XIX porque ésta provoca la no necesidad de una mano de obra, la quiebra del proletariado, de manera que se va produciendo en las ciudades un paro enorme que afecta a partes muy importantes de la población, es la época del capitalismo de mediados del S. XIX.

Frente a esta situación la clase popular actúa mediante sistemas comunitarios de protección.

Esa población en paro comienza a constituir sociedades de protección comunitaria, cooperativas de crédito, de vivienda, de consumo y sistemas de producción o cooperativas de trabajo.

Así, las sociedades cooperativas surgen, de una manera natural, de unas necesidades económicas concretas de poblaciones en Europa occidental.

El reconocimiento de las sociedades cooperativas se produce por primera vez en Inglaterra, dentro de la Ley de Sociedades industriales de 1852.

Al poco, se reconocen también por la Asamblea Francesa en la Ley de Sociedades de capital variable en 1867. En ese año se promulga en Portugal el Código de Sociedades Cooperativas de 1867 y en Alemania una Ley especial del Parlamento Federal de 1868 establece también la autonomía jurídica de las sociedades cooperativas.

El sistema se extiende en América Latina y llega a las colonias, India incluso hasta el incipiente desarrollo económico de Japón con la Ley de Cooperativas Japonesa de 1900.

A pesar de esa extensión del cooperativismo, en el derecho español las sociedades cooperativas no van a tener reconocimiento hasta 1931 (2. ${ }^{a}$ República) ello es debido a la falta de un reconocimiento liberal a lo largo de la 2. ${ }^{a}$ parte del s. XIX.

Tuvieron que actuar como sociedades de hecho, civiles, sin personalidad jurídica o acogiéndose a la Ley de Asociaciones de Derecho Privado de 1887. 
En el caso concreto de la economía agraria (hasta la década de los 40 fue fundamental) la vieja Ley de sindicatos agrícolas de 1906 permitió la constitución de cooperativas agrarias o de crédito agrario bajo el amparo de esa Ley sindical de sindicatos agrarios que permitió constituir las cajas rurales.

En 1931 la República proclamó la 1. ${ }^{a}$ Ley específica de cooperativas en España.

En los Estatutos de Autonomía (Catalán y Vasco) se reconocieron competencias exclusivas en materia cooperativa a pesar de que el C. Comercio de 1885 ya en el artículo 124 hacía referencia a la mercantilidad de las cooperativas.

A pesar de ello, como no había existido un desarrollo mercantil, a diferencia del derecho comparado, en los Estatutos de Autonomía, se dieron competencias exclusivas en materia cooperativa.

Cataluña en 1934 promulga su propia Ley de cooperativas (mejor técnicamente que la Ley General).

El Estatuto Vasco no pudo ser desarrollado porque antes de ello, llegó desafortunadamente la Guerra Civil, en 1938 una Ley derogatoria de la Junta de Burgos decidió derogar determinada legislación republicana que se consideraba especialmente peligrosa.

Tras el final de la Guerra Civil, en 1942 se promulgó una Ley de Cooperativas que establecía un sistema de cooperativismo sindical bajo el control de los antiguos sindicatos verticales y las sociedades cooperativas estuvieron controladas por ellos, obra sindical de cooperativas.

El sistema de cooperativas franquista fue idéntico al sistema de cooperativas de la U.R.S.S. En aquel sistema de la Ley del 42 se desarrolló el cooperativismo en España, con aquella ley se desarrolló el cooperativismo de Mondragón.

Lo que se produjo es una enorme distancia entre la práctica cooperativa y la legislación aplicable (antiliberal). Esto hasta dic. de 1974 antes de la muerte de Franco.

Como la distancia entre el cooperativismo real y la legislación no se reconocía, al final el régimen promulgó una Ley de cooperativas (19 dic. 1974) que por primera vez hablaba de un sistema económico democrático. 
A pesar de ello la Ley de 1974 tuvo que ser derogada por ser anterior al sistema de libertad económica de la C.E., que reconoce el principio de libre empresa y libre asociación.

A partir de la C.E. fue necesario articular una nueva legislación acorde a los principios de la C.E. Antes de ello, con el advenimiento del sistema de autonomías en varios Estatutos de Autonomía no sólo Vasco y Catalán se reconoció competencias exclusivas en materia cooperativa: Estatuto de Navarra, Estatuto de la C. Valenciana y el Andaluz. De forma que a partir de la Constitución y las leyes orgánicas de autonomía se pensó en establecer 6 grandes leyes de cooperativas. 5 para las Comunidades históricas y otra Ley General para el resto (las autonomías del 143).

En el entretanto el Parlamento Vasco promulgó la 1. ${ }^{a}$ Ley de Cooperativa Vasca y también con ello la $1 .{ }^{a}$ Ley de Cooperativas del período constitucional. Esa Ley de febrero del 83 planteó un problema de conflicto de normas porque establecía como criterio de aplicación de la ley el criterio de domicilio, sin embargo el criterio del domicilio podía implicar el peligro de la huida de ley. Por ello, el Gobierno Central para establecer un criterio de distribución competencial y legislativa planteó un recurso de inconstitucionalidad contra determinados preceptos de la Ley Vasca, el relativo al criterio de aplicación de la Ley: domicilio.

El abogado del recurso reclamó del T.C. que declarara inconstitucional todas las competencias exclusivas en materia cooperativa por ser materia reservada de la CE al ámbito central de acción y reclamó complementariamente la declaración de inconstitucionalidad a las de aplicación del criterio del domicilio.

Respecto a la $1 .{ }^{a}$ reconoce son sociedades mercantiles pero sin embargo no quiso extender más allá del reconocimiento en relación a la mercantilidad. De manera que el T.C. entró sólo en la parte relativa a la distribución competencial diciendo en esta Sentencia: 29 julio 1983.

Sentencia 29 julio 1983: Dice el TC que por supuesto las sociedades cooperativas como sociedades de derecho económico pueden intervenir en cualquier acto, en cualquier ámbito del Estado, todo ámbito en el que existiera Convenio de reciprocidad pero que en el ámbito interno de relación jurídica entre sociedades cooperativas y sus socios la aplicación de una ley autonómica no podía extenderse más allá del 
ámbito territorial estricto donde los socios realicen la actividad cooperativizada principal.

A Eroski se le aplica la Ley General 99 (porque también Eroski desempeña su actividad principal en otros puntos de España, se aplica la ley general también en Bilbao así como en Burgos, Cantabria...)

Si no es actividad principal sino actividad accesoria en los demás puntos de España y la actividad principal se desarrolla en P.V. por ej. Fagor, en Sevilla hay una delegación, se aplicaría la Ley Vasca incluso en los socios en Sevilla.

EI TC estableció un criterio fijo respecto a la distribución competencial en materia cooperativa:

- Intraterritorial: domicilio.

-Extraterritorial: Ley General Estado.

- Y como la interpretación de la Ley General se refería a la extraterritorialidad del objeto principal de la cooperativa el 23 dic. se promulgó la Ley 9/92 una ley orgánica para modificar los Estatutos de Autonomía. Esta ley extendió la competencia exclusiva por ley orgánica al resto de Comunidades Autónomas además de las 5 históricas, a las de 143 . A partir del 93 prácticamente todas las C.A fueron librando su ley de Cooperativas (Ley Gallega, Ley Cántabra de cooperativas, Extremeña...).

-El T.C habló de Comunidades de derecho general la única excepción era Ceuta y Melilla que son ciudades autónomas no Comunidades Autónomas.

-Artículo 2 Ley General: Artículo 2. Ámbito de aplicación.

La presente Ley será de aplicación:

-A las sociedades cooperativas que desarrollen su actividad cooperativizada en el territorio de varias Comunidades Autónomas, excepto cuando en una de ellas se desarrolle con carácter principal.

- A las sociedades cooperativas que realicen principalmente su actividad cooperativizada en las ciudades de Ceuta y Melilla.

\section{LA COMPETENCIA EN MATERIA DE DERECHO COOPERATIVO. MARCO CONSTITUCIONAL Y PROBLEMA LEGISLATIVO}

En la actualidad no existe una única Ley sino varias Leyes de cooperativas, dado que determinados territorios tienen norma propia. 
Para explicar esta situación debe tenerse en cuenta en primer lugar que la Constitución Española de 1978 arbitra un nueva organización territorial con respecto al régimen anterior; estamos hablando de «El Estado de las Autonomías». Con ello se divide España en 17 Comunidades autónomas, distribuyéndose las competencias entre éstas y el Estado. La propia Constitución dedica dos artículos al reparto competencial: el 148 se refiere a las competencias que pueden asumir las Comunidades Autónomas en sus respectivos Estatutos y el 149 recoge las competencias sobre las que el Estado se reserva la competencia exclusiva, entre ellas (en el párrafo 1.6) se señala la relativa a la Legislación mercantil.

Aprovechando la imprecisión existente sobre la calificación y el encuadramiento de la sociedad cooperativa, los Estatutos de Autonomía del País Vasco (artículo 10.23) y de Cataluña (artículo 9.21) atribuyen a sus Comunidades Autónomas competencia exclusiva en materia de cooperativas. Posteriormente, también asumen competencias legislativas en esta materia el Estatuto de Andalucía (artículo 13.20), el Estatuto de la Comunidad Valenciana (artículo 31.21) y la Ley reguladora del Régimen Foral de Navarra (artículo 44.7).

En base a la competencia asumida por los respectivos Estatutos de Autonomía, el legislador vasco primero y posteriormente el catalán ${ }^{1}$ aprueban sus respectivas Leyes cooperativas. La vasca fue objeto de un recurso de inconstitucionalidad, con que el Estado puso en entredicho la constitucionalidad de toda la delimitación competencial en materia cooperativa, aunque no contribuyó a modificar la situación previamente creada. El recurso se resuelve en sentencia 72/83 de 29 de julio. De ella se desprende que las partes centran el debate de la competencia legislativa del País Vasco (y por tanto de las demás Comunidades Autónomas que han asumido competencia exclusiva) en la consideración del denominado Derecho cooperativo como una parte o no del Derecho mercantil. La trascendencia que otorga a esta configuración se explica fácilmente porque la Constitución establece que el Estado tiene competencia exclusiva en materia de Legislación mercantil (artículo 149.1.6) y el Estatuto atribuye competencia exclusiva al País Vasco "conforme a la Legislación general en materia mercantil» (artículo 10.23), por lo que si la regulación sobre cooperativas hubiera de calificarse de mercantil, como sostiene el Abogado del Estado, la

1 Esta asunción se manifiesta en el País Vasco por Ley 1/1982 de 22 de febrero y en Cataluña por Ley 1/1983 de 9 de marzo. 
conclusión a la que habríamos de llegar sería la de que la de la competencia legislativa en materia cooperativas no corresponde a la Comunidad Autónoma. No obstante, el Tribunal, sin entrar en el fondo del asunto porque quizás no sea su misión, y sin tener en cuenta que aunque la cooperativa se calificase como sociedad civil la competencia también correspondería al Estado en base al artículo 149.1.8, señal que «(...) sin pretender ahora sentar afirmaciones de carácter general (...) sí podemos afirmar que en principio no es admisible una interpretación que conduzca a variar de contenido la competencia legislativa de la Comunidad en materia de cooperativas que hay que entender le viene atribuida por el artículo 10.23 de Estatuto». A esta conclusión: «(...) conduce la interpretación sistemática de los preceptos de la Constitución y del Estatuto, situado en el marco constitucional, y que prescinde de cualquier posición doctrinal acerca de si las cooperativas han de calificarse o no como sociedades mercantiles ya que la interpretación ha de situarse en el contexto del ordenamiento vigente» ${ }^{2}$.

En principio, sólo las cinco Comunidades referidas asumieron competencia legislativa exclusiva, aunque, en la actualidad, todas las Comunidades tiene transferida la competencia en la materia: mediante la Ley Orgánica 9/92, de 23 de diciembre, se transfirió la competencia a Asturias, Cantabria, Murcia, Aragón, Extremadura, Baleares, Madrid, Castilla-La mancha y Castilla-León, Galicia recibe la transferencia de la Ley Orgánica 16/95 y finalmente, Canarias mediante la Ley 4/96, de 30 diciembre.

Como consecuencia de esta delimitación territorial de competencias en materia de cooperativas, nos encontramos con una Ley estatal de cooperativas: Ley 27/1999, de 16 julio que sustituye a la anterior Ley de 3/1987 de 2 de abril, que se aplicará en aquellas Comunidades Autónomas que no han aprobado Ley de cooperativas y de forma supletoria en las Comunidades con norma propia, y con Leyes propias de las Comunidades que las han aprobado.

Sin embargo, inmediatamente después en la misma sentencia se plantea el problema del alcance territorial de las competencias autonómicas, ya que la Disposición final $1 .^{a}$ de la Ley vasca de cooperativas establece que «La presente ley se aplicará a todas las cooperativas

2 Fundamento jurídico $3 .^{\circ}$ de la sentencia mencionada. 
con domicilio en la Comunidad Autónoma del País Vasco, con independencia de su ámbito territorial de actuación».

El Abogado del Estado la impugnó porque: «(...) sitúa como punto de conexión el domicilio con independencia del ámbito territorial de actuación, con lo que cabe, a su entender, que cooperativas domiciliadas en el País Vasco, pero que ejerzan íntegramente sus actividades fuera del mismo, se sujeten a la Ley impugnada, con exclusión de cualquier otra». Para resolver esta cuestión el tribunal considera necesario partir del artículo 20.6 del EAPV que señala: «Salvo disposición expresa en contrario todas las competencias mencionadas en los artículos anteriores y otros del presente estatuto se entienden referidas al ámbito territorial del País Vasco». Al interpretar esta disposición el Tribunal entiende que las relaciones de carácter cooperativo que son las que, a su juicio, determinan la competencia, son las que habrán de desarrollarse en el ámbito territorial del País Vasco. Y son consideradas relaciones de carácter cooperativo las relaciones de las cooperativas con sus socios, debiendo asimilarse a ellas, como sucede en el caso previsto en el artículo 57.2 de la Ley impugnada, relativo al supuesto en que las cooperativas de consumo pueden suministrar a los no socios.

Para acabar de precisar la cuestión la Sentencia señala, además, que: «(...) la cooperativa como persona jurídica ha de establecer relaciones jurídicas externas con terceros que no pueden encuadrarse dentro de las funciones típicas de las mismas y que tienen un valor instrumental y necesario para la consecución del fin social. Así, por ejemplo, una cooperativa de consumo habrá de comprar los productos que vende a sus socios, y en determinados supuestos a terceros, y una cooperativa de producción habrá de vender lo producido. Es una actividad inherente a determinadas cooperativas el poder establecer relaciones como las señaladas, actividad que realiza exactamente igual que otra persona jurídica. La competencia material de la Comunidad respecto a las cooperativas no incide directamente en estas relaciones... Se trata, en definitiva, de actividades y relaciones instrumentales en las que la cooperativa actúa como cualquier otra persona jurídico privada, en el ámbito territorial del País Vasco o fuera del mismo».

Como conclusión señala el Tribunal: «(...) la Comunidad Autónoma del País Vasco tiene competencia para regular por Ley las cooperativas que lleven a cabo su actividad societaria típica en los términos ya expuestos, dentro del territorio de la Comunidad, aun cuando esta- 
blezcan relaciones jurídicas o realicen actividades de carácter instrumental fuera del territorio de la misma» (fundamento jurídico 4. $\left.{ }^{\circ}\right)^{3}$.

\section{LEY 1/2000, DE 29 DE JUNIO, DE MODIFICACIÓN DE LA LEY DE COOPERATIVAS DE EUSKADI}

\section{Introducción}

\section{I.1. ¿Qué supuso la Ley de Cooperativas de Euskadi 4/1993 de 24 de junio?}

Históricamente, la Ley de Cooperativas de Euskadi 4/1993 de 24 de junio implicó un gran cambio con respecto a la anterior Ley del año 82. Las líneas directrices de la nueva normativa iban en la dirección de adecuar el entramado jurídico a la estructura, tamaño y modernidad que presentaban las Cooperativas vascas a principios de los años noventa. Y a la experiencia de Mondragón.

Esta Ley 4/1993, de Cooperativas de Euskadi, en sus siete años de vigencia, se ha significado como una regulación propicia para el desarrollo empresarial y societario del moderno cooperativismo vas$\mathrm{co}$, en la medida en que establece:

- una regulación que le posibilita una evolución reforzada del conjunto de sus factores productivos

- y le dota de una mayor agilidad para que las cooperativas puedan competir en un mercado como el actual, caracterizado por su cambio permanente.

Por otra parte, la Ley 4/1993, de 24 de junio, que ha sido un referente claro para otras legislaciones cooperativas posteriores en el ámbito estatal, tuvo especial cuidado, en el conjunto de su texto, de fundamentar la regulación de todo el entramado societario-empresarial en la observancia de los valores y principios cooperativos proclamados por la Alianza Cooperativa Internacional.

Desde este punto de vista, entendemos por cooperativa una asociación autónoma de personas que se han unido de forma voluntaria

3 Con posterioridad, y en relación con este tema aunque siempre partiendo de las pautas marcadas por esta sentencia, se dictaron las sentencias 44/84, de 27 de marzo, 165/1985, de 5 de diciembre y la sentencia 88/1989, de 11 de mayo. 
para satisfacer sus necesidades y aspiraciones económicas, sociales y culturales en común mediante una empresa de propiedad conjunta y de gestión democrática.

En suma, la ley satisface básicamente el, en ocasiones, difícil equilibrio entre mantener la identidad cooperativa reflejada en el cumplimiento de los principios y reglas propias del cooperativismo y, simultáneamente, abordar los retos empresariales con una cobertura legal sin la cual hubieran tenido dificultades de encaje y desarrollo para el desempeño de su actividad de forma eficiente.

En los cinco años posteriores, los representantes de las Cooperativas se habían ido percatando de una serie de desajustes que presentaba la nueva Ley y que, en su opinión, poseían la suficiente importancia y enjundia como para que se solventasen por la vía legislativa.

Tras estos años de aplicación de la ley, y atendiendo a las peticiones del movimiento cooperativo vasco, se planteó un debate acerca de si la norma en vigor satisfacía íntegramente las finalidades que con ella se pretendían para cumplir con el mandato constitucional recogido en el artículo 129, apartado 2, de la Constitución Española, de fomento del cooperativismo, o si, por el contrario, procedía acomodar la vigente regulación a las necesidades de los emprendedores y de los proyectos empresariales que iban surgiendo, facilitando la constitución de nuevas cooperativas a la vez que consolidando, mediante mejoras técnicas y de ajuste puntuales, las ya existentes en el País Vasco.

Y ésta es la finalidad de la presente ley de reforma parcial de la Ley 4/1993, de 24 de junio, de Cooperativas de Euskadi, para lo cual regula las reformas que posteriormente expondremos.

\section{Fundamentos de la reforma}

Personalidades destacadas en materia de derecho cooperativo como Alfredo IsPizUA, Director de Economía Social del Gobierno Vasco, y AdRIÁn CelAYA, responsable de los Servicios Jurídicos de Mondragón Corporación Cooperativa, coinciden en señalar que la nueva Ley de Cooperativas de Euskadi 1/2000 aprobada el 29 de Junio de este año por todos los partidos políticos presentes en el Parlamento Vasco no se trata de una modificación estructural de la Ley, como fue la de 
1993 con respecto a la de 1982, sino que nos encontramos ante una reforma puntual que aborda una serie de aspectos concretos, y entre ellos, da respuesta a la sensibilidad que existía en las organizaciones cooperativas con respecto a la necesidad de reducir el número mínimo de socios para la constitución de nuevas cooperativas, que con la actual reforma pasa de cinco a tres socios.

II.1. Los principales ámbitos sustantivos que aborda la actual reforma son:

— fomentar la constitución de nuevas cooperativas,

- una apuesta por una mayor cooperativización,

- una mejora en el régimen del capital,

- dar ropaje jurídico a los Grupos Cooperativos

- un reconocimiento de la igualdad de trato a los socios trabajadores con respecto a los trabajadores por cuenta ajena, en materia de incentivos a la creación y estabilidad del empleo, principalmente.

\section{II.2. El período de gestación de la Ley}

AlfREDo IsPizua apunta que el período de gestación de la actual reforma se inició desde el propio Movimiento Cooperativista, y se retrotrae a 1997, aunque formalmente fue planteado a principios de 1999. Se trataba de una demanda del sector, y que partió de la Federación de Cooperativas de Trabajo Asociado de Euskadi con el respaldo de la Confederación de Cooperativas de Euskadi.

La Ley de Cooperativas $1 / 2000$ ha sido la primera Ley aprobada por el Parlamento Vasco en 2000 con los votos de todos los partidos políticos, tanto de la coalición del Gobierno como de la oposición, y es una de las dos únicas leyes que han sido aprobadas por la Cámara Vasca excluida la de presupuestos.

Podemos señalar a este respecto que es significativo que en momentos de gran inestabilidad política como los que se estaban viviendo, fuera precisamente la legislación cooperativa la que fue capaz de aglutinar a todos los grupos políticos. Se trata de un hecho que revela la gran capacidad aglutinadora que atesora el Cooperativismo, en el que sensibilidades muy distintas convergen o son capaces de converger en base a objetivos comunes de solidaridad y desarrollo económico. 


\section{II.3. Más posibilidades de crear pequeñas Cooperativas}

Es un hecho indiscutible que los promotores de una iniciativa empresarial fijan la tipología social del proyecto que pretenden desarrollar en el momento de la constitución.

Precisamente es en el momento del nacimiento cuando la cuenta de explotación del grupo humano es más ajustado. Y se constataba que la forma jurídica de cooperativa, entre el conjunto de fórmulas jurídicas existentes, era a la que se exigía un mayor número de socios fundadores.

A su vez, la Federación de Cooperativas de Trabajo Asociado de Euskadi encargó un análisis al Eustat (Centro Vasco de Estadística) para que estudiara por tipologías (autónomos, SL, SA,...), cuál había sido la media de socios fundadores en los tres últimos años. El resultado obtenido revelaba que la media de socios fundadores era 1,7; mientras que la Ley de Cooperativas 4/93 marcaba un número mínimo de cinco.

Por otra parte, se constataba que el número de nuevas promociones de Cooperativas había tenido una curva ascendente desde 1985 hasta 1993, mientras que a partir de ese año la curva coge un derrotero descendente, siendo cada vez más acusado. Con estos antecedentes, existía desde hace tiempo en el Movimiento Cooperativo una sensibilidad para que se redujera el número mínimo de socios fundadores. La Ley 1/2000 recoge esta demanda y reduce el número mínimo de socios fundadores de cinco a tres.

En opinión de los estudiosos destacados, en el sector existía una conciencia de que había una serie de cuestiones legislativas que eran claves a la hora de que se crearan más Cooperativas.

Entre ellas, la disminución del número mínimo para la constitución de una Cooperativa. En Cataluña ya se habían percatado de este handicap y ya habían empezado a tomar medidas con buenos resultados. A partir de la constatación del sector y de la sensibilidad demostrada por el Gobierno Vasco, se produjo la reforma y la disminución del número mínimo de socios fundadores de cinco a tres.

\section{II.4. Hacia una mayor cooperativización}

De acuerdo con la filosofía y los principios del Movimiento Cooperativo en las Cooperativas se limita el porcentaje de trabajadores por 
cuenta ajena al existir una vocación final de que los recursos humanos participen, no sólo ofreciendo su esfuerzo a cambio de una retribución, sino como auténticos agentes protagonistas de las Cooperativas.

La reforma de la Ley de Cooperativas, al abordar esta cuestión, hace hincapié en la filosofía inherente al Cooperativismo y apuesta por una mayor cooperativización en las Cooperativas. En este sentido, dos son las medidas adoptadas:

- Por un lado, se reduce el porcentaje de horas/año realizadas por trabajadores por cuenta ajena, respecto del realizado por los socios trabajadores de la Cooperativa, que del $30 \%$ pasa al $25 \%$.

- Por otro, se promociona la figura del socio de duración determinada, que aunque tiene un compromiso social limitado en el tiempo, su vocación es ser una figura de tránsito hacia la de socio de duración indeterminada, y que ahora puede aumentar su porcentaje máximo en relación con los socios de duración indeterminada, de forma que puede llegar al $50 \%$ de las horas/año realizadas por los socios trabajadores indefinidos, las horas/año desarrolladas por los socios de duración determinada y las de los trabajadores por cuenta ajena.

Tanto Adrián Celaya como Alfredo Ispizua hacen una reflexión de fondo sobre los pros y los contras que se abren con la actual reforma en el ámbito de la contratación.

Entendemos que existen dos variables que hay que tener muy en cuenta a la vez:

-En primer lugar, desde el punto de vista normativo, y ante las nuevas posibilidades abiertas, hay que intentar al máximo que a la eventualidad que sea necesaria generar por razones económico-empresariales en las Cooperativas se le dote de derechos societarios a través de los socios de duración determinada.

- A su vez, hay que mentalizar a las Cooperativas para que controlen y limiten, dentro de lo posible, esa eventualidad, ya que una eventualidad muy grande suele implicar problemas a largo plazo: de incentivación y motivación de las personas, de eficacia, de capacidad de formación de los eventuales, de implicación.

-En definitiva, es conveniente y recomendable que las Cooperativas, cuando necesiten contratar a personas eventuales - sólo cuando realmente lo necesiten-, utilicen la figura del socio de 
duración determinada y no el de cuenta ajena. Por otra parte, transcurridos tres años, el socio de duración determinada puede solicitar su conversión en ilimitada y en todo caso, transcurridos cinco años, se convertirá automáticamente en socio de duración indeterminada (la Ley 1/2000 recoge que a las cooperativas muy pequeñas, y en concreto las constituidas por siete o menos socios, se les permite que puedan tener hasta dos trabajadores por cuenta ajena).

\section{II.5. Mejora del régimen del capital}

La reforma de la Ley de Cooperativas mejora el régimen del capital y abre nuevas posibilidades de financiación tanto hacia fuera como hacia dentro de la Cooperativa, sin que ello afecte al capital social tradicional, la aportación de los socios, etcétera.

En este sentido, los socios no se van a ver afectados en su condición de tal, ya que la condición de socio no está vinculada a la aportación de capital.

El capital tradicional de las Cooperativas no sufre ninguna modificación como consecuencia de la reforma pero sí se abren nuevas posibilidades de actuación para mejorar las posibilidades de captación y acumulación de capital.

Siempre hay que tener en cuenta que las aportaciones de capital son sin derechos de voto, con lo cual no se altera la estructura organizativa y de poder, ni se cuestiona la esencia cooperativa. Esta adaptación nace como consecuencia de las dificultades tradicionales de las Cooperativas para la captación y acumulación de capitales, lo que estaba directamente relacionado con su régimen jurídico. Se pretende facilitar la captación de capitales tanto de socios como de no socios.

De este modo, con la Ley 1/2000 se abren muchas posibilidades teóricas, aunque es necesario ir avanzando poco a poco. Son experiencias que ya se estaban aplicando en la práctica en algunas Cooperativas y lo único que se ha hecho ha sido mejorar su cobertura jurídica.

\section{II.6. Cobertura jurídica para los Grupos Cooperativos}

La ley abre nuevas posibilidades que habrá que ir gestionando día a día. Es muy importante que los gestores financieros de las Cooperativas conozcan las nuevas posibilidades y empiecen a gestionarlas. 
En las leyes reguladoras del cooperativismo en la Comunidad Autónoma Vasca, la Ley 1/2000 es la primera que regula los Grupos Cooperativos. Un grupo cooperativo es un conjunto de Cooperativas que se ponen de acuerdo para poner determinadas facultades de decisión en común a través de una entidad de cabecera, con independencia de la fórmula jurídica que esa entidad de cabecera elija. Sin embargo, debe respetarse necesariamente que el conjunto de las vinculaciones y funcionamiento entre las cooperativas sea cooperativo.

Los Grupos representan una fórmula adecuada y muy propia de la tradición cooperativa para dar respuesta a las necesidades complementarias de la creación de Cooperativas de segundo grado o de otros instrumentos de intercooperación.

Tanto Alfredo Ispizua como Adrí́n Celaya aclaran que no se trata de la creación de una nueva figura ajena a la realidad cooperativa existente, sino que se trata de clarificar y de dar seguridad jurídica a lo que ya se estaba haciendo dentro del Movimiento Cooperativo Vasco.

La actual reforma en este punto se remonta al tradicional olvido de los legisladores con el socio trabajador. Existía una sensibilidad tanto en el sector como en el Gobierno Vasco para que se resolviese este problema dentro de la CAV.

\section{II.7. Evitar discriminaciones al socio trabajador}

Las medidas que se adoptan para evitar la discriminación entre los trabajadores por cuenta ajena y los socios cooperativistas se refieren principalmente al fomento del empleo.

Se trata de que se eliminen los obstáculos que históricamente padecían las Cooperativas en relación a las restantes formas jurídicas. Por ejemplo, el rejuvenecimiento de plantillas hay que modificarlo y acomodarlo a la realidad cooperativa. En este sentido, en este momento se está tramitando una Orden del Departamento de Trabajo del Gobierno Vasco para regular con carácter específico las renovaciones de la plantilla dentro de las Cooperativas.

Este es un ejemplo más de la labor que se está haciendo desde la Administración Vasca para que los socios cooperativistas tengan un trato similar al resto de los trabajadores por cuenta ajena, recalca Alfredo Ispizua, Director de Economía Social del Gobierno Vasco. 


\section{Novedades introducidas por la ley $1 / 2000$ de 29 de junio respecto articulado de la Ley 4/1993, de 24 de junio}

\section{III.1. Novedades específicas}

1. En primer lugar nos referiremos al régimen jurídico de los socios y especialmente al número de socios. Esta Ley 1/2000 reduce de cinco a tres el número mínimo de socios para constituir cooperativas de primer grado, en pro de facilitar la constitución de nuevas cooperativas.

Siguiendo esta línea diremos que en opinión de importantes estudiosos de esta materia como son, los ya mencionados Alfredo ISPIZUA, Director de Economía Social del Gobierno Vasco, y AdRIÁn CELAYA, responsable de los Servicios Jurídicos de MCC, (a quienes tuvimos la oportunidad de conocer sus opiniones en diversas conferencias en nuestra Universidad) consideran que la reforma de la Ley de Cooperativas 1/2000 responde a las demandas y sensibilidad que existía en el Movimiento Cooperativo Vasco en los últimos años. Y crea, entre otros apartados, mejores condiciones para la constitución de nuevas Cooperativas al reducirse el número mínimo de socios fundadores de cinco a tres.

Su propósito era favorecer la creación de nuevas Cooperativas. Parecía razonable que el número mínimo de socios, cinco, se redujera ya que esa era la tendencia en el derecho cooperativo del Estado, y no conculca dogmática cooperativa alguna.

Además, había datos suficientes, a raíz de los estudios realizados por la Federación, que mostraban que la inmensa mayoría de las iniciativas empresariales, en general, no nacían con muchos socios (dos o tres), y con ello se facilita emprender cooperativamente

Así la reforma introducida en la ley del 93 sería la siguiente:

Artículo tercero. Se da nueva redacción al párrafo 1 del artículo 19 de la Ley 4/1993, de 24 de junio, de Cooperativas de Euskadi, que queda redactado de la manera siguiente:

Artículo 19.1. Pueden ser socios de las cooperativas de primer grado tanto las personas físicas como las jurídicas, públicas o privadas, con las salvedades establecidas en el título II de la presente ley.

En las cooperativas de segundo o ulterior grado se estará a lo dispuesto en el artículo 128.1. 
En el momento de la constitución, las cooperativas de primer grado habrán de estar integradas, al menos, por tres socios de la clase de la cooperativa que se constituye. Las de segundo o ulterior grado deberán contar entre sus socios fundadores con dos sociedades cooperativas como mínimo.

2. En segundo lugar y consecuentemente, se reduce a tres mil euros el capital social mínimo.

Dicha reducción del capital social mínimo tiene como objetivo facilitar la constitución de nuevas cooperativas.

Artículo primero. Se da nueva redacción al artículo 4 de la Ley 4/1993, de 24 de junio, de Cooperativas de Euskadi, que queda redactado de la manera siguiente:

Artículo 4. Capital social mínimo.

El capital social mínimo no será inferior a tres mil euros (499.158 pta.) y se expresará en esta moneda. En la cuantía correspondiente a dicho mínimo legal, el capital deberá hallarse íntegramente desembolsado desde la constitución de la cooperativa.

3. Como tercera modificación destacamos que permite que, cuando en el Consejo Rector de la cooperativa se hayan establecido reservas de puestos, cada colectivo de socios afectado tenga derecho a elegir directamente en la Asamblea el número de consejeros que le correspondan, sin intervenir en la elección de los restantes miembros del Consejo.

Artículo sexto. Se da nueva redacción al párrafo 3 del artículo 41 de la Ley 4/1993, de 24 de junio, de Cooperativas de Euskadi, que queda redactado de la manera siguiente:

Artículo 41. 3. Los administradores serán elegidos por la Asamblea General, por el mayor número de votos válidamente emitidos en votación secreta.

Cuando en el Consejo Rector de la cooperativa se hayan establecido reservas de puestos conforme a lo previsto en el número 4 del artículo 45, salvo disposición contraria de los Estatutos, cada colectivo de socios afectado tendrá derecho a elegir directamente en la Asamblea el número de consejeros que le corresponda sin intervenir en la elección de los restantes miembros del Consejo.

4. En cuarto lugar, se flexibiliza la constitución de la Asamblea General en determinados tipos de cooperativas como las agrarias y las de consumo, evitando, en último término, la paralización del órgano 
supremo de la cooperativa. En este sentido, se prevé la existencia de una tercera convocatoria para dichas cooperativas, cualquiera que sea el número de votos presentes o representados, que sólo podrá celebrarse tras no haberse alcanzado los quórums previstos en las dos anteriores.

Artículo segundo. Se da nueva redacción al apartado I) del párrafo 1 del artículo 13 de la Ley 4/1993, de 24 de junio, de Cooperativas de Euskadi, que queda redactado de la manera siguiente:

Artículo 13.1) Forma de publicidad y plazo para convocar la Asamblea General, ordinaria o extraordinaria, en primera o segunda convocatoria, o bien en tercera convocatoria para el caso de las cooperativas de consumo y agrarias, así como el régimen de adopción de acuerdos, tal como se recoge en el artículo 34.2 de esta ley.

Artículo quinto. Se da nueva redacción al número 2 del artículo 34 de la Ley 4/1993, de 24 de junio, de Cooperativas de Euskadi, que queda redactado de la manera siguiente:

Artículo 34.2. La Asamblea General quedará válidamente constituida, en primera convocatoria, cuando estén presentes o representados la mayoría de votos, y en segunda convocatoria cuando estén presentes o representados al menos socios que ostenten el diez por ciento de los votos o cien votos. Salvo previsión estatutaria en contra, basta alcanzar dicho quorum al inicio de la sesión. No obstante, los Estatutos de las cooperativas de consumo y agrarias podrán prever una tercera convocatoria por la que la Asamblea General podrá celebrarse cualquiera que sea el número de votos presentes o representados.

5. Otra modificación sería en relación con el capital social, se regula el régimen de las denominadas aportaciones financieras subordinadas, para allegar financiación fundamentalmente externa — sin obviar la interna - con carácter de permanencia que integre los recursos propios de la cooperativa (considerándose capital social), sujetas a las condiciones que se establezcan.

Artículo octavo. 1. Se adiciona un nuevo número 5 al artículo 57 de la Ley 4/1993, de 24 de junio, de Cooperativas de Euskadi, con la siguiente redacción:

Artículo 57.5. Se consideran financiaciones subordinadas las recibidas por las cooperativas que, a efectos de prelación de créditos, se sitúen detrás de todos los acreedores comunes.

Independientemente de su denominación o formalización jurídica, tendrá la consideración de capital social cualquier aportación fi- 
nanciera subordinada contratada por la cooperativa con socios o terceros cuyo vencimiento no tenga lugar hasta la aprobación de la liquidación de la misma, sin que le sea de aplicación, salvo pacto en contrario, lo dispuesto en los artículos 59 a 63 de esta ley. Dichas aportaciones o participaciones podrán ser reembolsables o adquiridas en cartera mediante mecanismos financieros de garantía equivalentes a los establecidos para las participaciones o acciones en las sociedades de capital, incluyendo las opciones previstas en la segunda directiva 77/91, o en los términos que reglamentariamente se establezcan.

Estas aportaciones, cuya retribución podrá ser fija, variable o participativa, se representarán por medio de títulos o anotaciones en cuenta, que podrán tener la consideración de valores mobiliarios si así se prevé en el acuerdo de emisión, en cuyo caso su régimen jurídico se ajustará a la normativa aplicable a estos activos financieros.

Estas aportaciones en ningún caso atribuirán derechos de voto en la Asamblea General ni de participación en el órgano de administración.

La emisión o contratación de estas aportaciones deberá ser ofrecida, en cuantía no inferior al 50 por ciento, a los socios y trabajadores asalariados de la cooperativa antes de ofrecerse a terceros. Tal oferta tendrá publicidad equivalente a la establecida en la cooperativa para la convocatoria de las Asambleas Generales.

2. Como consecuencia de la adición anterior, el número 5 del artículo 57 de la Ley 4/1993, de 24 de junio, de Cooperativas de Euskadi, pasa a ser el número 6 de este artículo, con la siguiente redacción:

6. Lo establecido en los números 1 a 5 de este artículo será aplicable a las cooperativas de crédito y de seguros sólo cuando la normativa sobre unas u otras no lo impida.

Artículo séptimo. Se modifica el artículo 57.4 de la Ley 4/1993, de 24 de junio, de Cooperativas de Euskadi, que quedaría redactado de la siguiente manera:

4. El importe total de las aportaciones de cada socio en las cooperativas de primer grado, salvo que se trate de sociedades cooperativas o socios colaboradores, no puede exceder del tercio del capital social. No estarán sujetas a esta limitación las cooperativas cuyo número de socios no sea superior a diez».

6. Igualmente supone una modificación de la Ley 4/1993 el hecho de que se establezca un nuevo régimen jurídico respecto a las denominadas participaciones especiales, coherente con la modificación anterior. 
Artículo noveno. Se da nueva redacción al artículo 64 de la Ley 4/1993, de 24 de junio, de Cooperativas de Euskadi, que queda redactado de la manera siguiente:

Artículo 64. Participaciones especiales.

1. Serán participaciones especiales las financiaciones subordinadas expresamente acogidas a la regulación establecida en este artículo, en las que los suscriptores —salvo lo previsto en el número 4 de este artículo- sean necesariamente entidades no cooperativas, el reembolso no tenga lugar hasta que transcurran al menos cinco años desde la emisión y la remuneración se establezca en función de los resultados de la cooperativa.

2. Las restantes características de estas participaciones serán establecidas libremente en el momento de su emisión, sin que en ningún caso atribuyan derechos de voto en la Asamblea General ni de participación en el órgano de administración.

3. Lo establecido en este artículo sólo será de aplicación a las cooperativas de crédito y seguros cuando la normativa sobre unas u otras no lo impida.

4. La emisión o contratación de las participaciones especiales deberá ser ofrecida, en cuantía no inferior al 50 por ciento, a los socios y trabajadores asalariados de la cooperativa antes de ofrecerse a terceros. Tal oferta tendrá publicidad equivalente a la establecida en la cooperativa para la convocatoria de las Asambleas Generales.

5. Independientemente de su denominación, las participaciones que no se sometan expresamente a la regulación de este artículo, se regirán por el libre pacto y por lo dispuesto para el capital social en el artículo 57 o para otras financiaciones en el artículo 65.

7. Como séptima modificación se fomenta la vinculación societaria, mediante la ampliación de los límites de socios de duración determinada, con una paralela reducción, en su caso, de la contratación por cuenta ajena, fijándose así mismo un nuevo límite máximo de las horas/año realizadas en conjunto por ambos colectivos.

Artículo cuarto. Se modifica el artículo 26.2 de la Ley 4/1993, de 24 de junio, de Cooperativas de Euskadi, que quedaría redactado de la siguiente manera:

26. 2. La pertenencia del socio a la cooperativa tendrá carácter indefinido.

No obstante, si lo prevén los Estatutos y se acuerda en el momento de la admisión, podrán establecerse vínculos sociales de duración determinada. Los derechos y obligaciones propios de tales vínculos serán equivalentes a los de los demás socios y serán regula- 
dos en los Estatutos. El conjunto de estos socios no podrá ser superior a la quinta parte de los socios de carácter indefinido de la clase de que se trate, ni de los votos de estos últimos en la Asamblea General, salvo en las cooperativas de trabajo asociado o en las que, siendo de otra clase, tengan socios de trabajo, que podrán superar dichas proporciones siempre que el número de horas/año de trabajo realizadas en conjunto por los socios de duración determinada, y los trabajadores por cuenta ajena, no llegue al $50 \%$ del total de horas/año realizadas por los socios trabajadores o de trabajo de carácter indefinido.

Los socios trabajadores o de trabajo titulares de contratos societarios de duración determinada que acumulen un período de tres años en esa situación tendrán la opción de adquirir la condición de socio de duración indefinida, y si dicho periodo alcanza cinco años la adquirirán en todo caso, para lo que deberán cumplir los demás requisitos estatutariamente establecidos para los socios de duración indefinida.

8. Otra novedad supone en cuanto al límite porcentual que no puede ser superado por los trabajadores con contrato de trabajo por cuenta ajena, se modifica el porcentaje y el criterio para su determinación y se incluyen determinadas excepciones, en aras de la flexibilidad, de la operatividad, sobre todo en pequeñas cooperativas, y de la seguridad jurídica, por una parte, y del fomento de la contratación societaria de duración determinada, por otra.

9. Como novena modificación se posibilita una respuesta pragmática y operativa a los problemas concretos que plantea la aplicación del principio de participación en los resultados positivos de la cooperativa respecto a los trabajadores asalariados que no tengan opción a ser socios.

Artículo duodécimo. Se da nueva redacción al párrafo segundo del número 5 del artículo 99 de la Ley 4/1993, de 24 de junio, de Cooperativas de Euskadi, que queda redactado de la manera siguiente:

Artículo 99. 5. Los asalariados que no tengan opción a ser socios, o mientras no puedan ejercitarla, participarán en los resultados de la cooperativa, cuando éstos fueran positivos, en la proporción que han de definir los Estatutos, que en ningún caso será inferior al veinticinco por ciento del retorno cooperativo reconocido a los socios de igual o equivalente clasificación profesional. Cuando el asalariado cause baja dicha participación podrá calcularse sobre las últimas cuentas anuales aprobadas por la Asamblea General. Esta participación en resultados tendrá el carácter que señala el artículo 67.5 de esta ley. 
10. Décima novedad sería el que se equipara los derechos de los socios trabajadores con los trabajadores por cuenta ajena en los supuestos de subrogaciones en casos de contratas y concesiones administrativas, para así proteger el puesto de trabajo de los socios trabajadores afectados por la sustitución de la cooperativa por otra empresa en la contrata o concesión y para, a su vez, evitar la traba que el no reconocimiento supondría de cara a fomentar la iniciativa privada en forma cooperativa dentro del sector de gestión y prestación de servicios públicos.

Artículo decimocuarto. Se adiciona un nuevo número 9 al artículo 99 de la Ley 4/1993, de 24 de junio, de Cooperativas de Euskadi, con la siguiente redacción:

Artículo 99. 9. De conformidad con lo establecido en el artículo 86.2 de la Ley 27/1999, de 16 de julio, de Cooperativas, cuando una cooperativa de trabajo asociado cese, por causas no imputables a la misma, en una contrata de servicios o concesión administrativa y un nuevo empresario se hiciese cargo de ésta, los socios trabajadores que vinieran desarrollando su actividad en la misma tendrán los mismos derechos y deberes que les hubieran correspondido, de acuerdo con la normativa vigente, si hubieran prestado su trabajo en la cooperativa en la condición de trabajadores por cuenta ajena.

Los trabajadores que se hallaran en la situación del párrafo anterior tendrán, durante un plazo de cinco años, derecho preferente de reingreso en su cooperativa de origen si en ésta se crearan nuevos puestos de trabajo de contenido similar al que ocupaban.

11. Hemos de destacar que en materia de suspensión y extinción de contratos de socios trabajadores se introducen, en coherencia con la regulación laboral vigente, los nuevos términos (causas técnicas, organizativas o de producción) acuñados con posterioridad a la entrada en vigor de la Ley 4/1993, de 24 de junio, de Cooperativas de Euskadi.

Artículo decimoquinto. Se da nueva redacción al artículo 103 de la Ley 4/1993, de 24 de junio, de Cooperativas de Euskadi, que queda redactado de la manera siguiente:

Artículo 103. Suspensión o baja obligatoria por causas económicas, técnicas, organizativas, de producción o de fuerza mayor.

1. En las cooperativas de trabajo asociado, cuando se produzcan causas económicas, técnicas, organizativas, de producción o de fuerza mayor que así lo hagan necesario, se podrá suspender temporalmente la obligación y el derecho del socio trabajador a prestar su trabajo, con pérdida de los derechos y obligaciones económicos 
de dicha prestación, conservando el resto de sus derechos y obligaciones de socio.

Para ello, la Asamblea General deberá declarar la necesidad de que, por alguna de las mencionadas causas, pasen a la situación de suspensión la totalidad o parte de los socios trabajadores que integran la cooperativa, así como el tiempo que ha de durar la suspensión, y designar los socios trabajadores concretos que han de quedar en situación de suspensión.

Al cesar las causas de suspensión, el socio trabajador recobrará plenamente sus derechos y obligaciones.

2. Cuando por la gravedad de las causas económicas, técnicas, organizativas, de producción o de fuerza mayor que concurran sea necesario, para mantener la viabilidad económica de la cooperativa, reducir con carácter definitivo el número global de puestos de trabajo o el de determinados colectivos o grupos profesionales, la Asamblea General deberá determinar el número e identidad de los socios que habrán de causar baja en la cooperativa. La baja, en estos casos, tendrá consideración de obligatoria justificada, y los socios cesantes tendrán derecho a la devolución inmediata de sus aportaciones al capital social, conservando un derecho preferente al reingreso si se crean nuevos puestos de trabajo de contenido similar al que ocupaban en los dos años siguientes a la baja.

12. La duodécima novedad que incluimos sería en relación con las cooperativas de segundo grado o ulterior grado, teniendo en cuenta su especificidad derivada de la condición de cooperativas -y otras personas jurídicas, en su caso- de sus socios, flexibiliza el régimen establecido respecto a los ingresos y bajas de socios en cooperativas de segundo grado; establece nuevos criterios respecto a la realización de aportaciones obligatorias al capital, y flexibiliza, en un doble sentido, el tratamiento respecto a la estructura orgánica en las cooperativas de segundo grado: en primer lugar permitiendo a los Estatutos establecer mínimos y máximos a la representación de los miembros de las cooperativas de segundo grado, sin perjuicio de la aplicación del criterio básico de proporcionalidad, que no se pone en cuestión; en segundo lugar abriendo la posibilidad de ampliar el número de miembros del Consejo Rector para dar cabida en él a todos los socios, o al menos a una representación de los mismos, asegurando la presencia suficiente de los diversos tipos de socios.

13. Como novedad decimotercera se abre una nueva vía de intercooperación, reconociendo el carácter cooperativo de operaciones que contribuyen al cumplimiento del objeto social. 
Artículo decimonoveno. Se adiciona un nuevo artículo 134 bis de la Ley 4/1993 de 24 de junio, de Cooperativas de Euskadi, con la siguiente redacción:

Artículo 134 bis. Las cooperativas podrán suscribir con otras acuerdos intercooperativos en orden al cumplimiento de sus objetos sociales. En virtud de los mismos, la cooperativa y sus socios podrán realizar operaciones de suministro, entregas de productos o servicios en las otras cooperativas firmantes del acuerdo, teniendo tales hechos la misma consideración que las operaciones cooperativizadas con los propios socios.

14. Igualmente se crea una nueva figura jurídica inexistente hasta ahora, cual es la de los grupos cooperativos, asentada en el principio de intercooperación, con la finalidad de impulsar nuevas modalidades de integración empresarial de las sociedades cooperativas ante los retos cada vez más exigentes de tener que operar en mercados progresivamente más globalizados; mercados que demandan nuevas soluciones jurídicas, que las existentes no satisfacen.

Como decimos, la Ley 1/2000 es la primera que regula los Grupos Cooperativos.

Un grupo cooperativo es un conjunto de Cooperativas que se ponen de acuerdo para poner determinadas facultades de decisión en común a través de una entidad de cabecera, con independencia de la fórmula jurídica que esa entidad de cabecera elija. Sin embargo, debe respetarse necesariamente que el conjunto de las vinculaciones y funcionamiento entre las cooperativas sea cooperativo.

Los Grupos representan una fórmula adecuada y muy propia de la tradición cooperativa con la finalidad de dar respuesta a las necesidades complementarias de la creación de Cooperativas de segundo grado o de otros instrumentos de intercooperación.

Artículo vigésimo. Se adiciona un nuevo artículo 135 bis a la Ley 4/1993, de 24 de junio, de Cooperativas de Euskadi, con la siguiente redacción:

Artículo 135 bis. Grupos cooperativos.

1. Se entiende por grupo cooperativo, a los efectos de esta ley, el conjunto formado por varias sociedades cooperativas, cualquiera que sea su clase, y la entidad cabeza de grupo, que ejercita facultades o emite instrucciones de obligado cumplimiento para las cooperativas agrupadas, de forma que se produce una unidad de decisión en el ámbito de dichas facultades. El grupo deberá ajustar su fun- 
cionamiento a los principios cooperativos, de conformidad con lo previsto en el artículo 1.2 de la presente ley.

2. La emisión de instrucciones podrá afectar a distintos ámbitos de gestión, administración o gobierno, entre los que podrá incluirse:

a) El establecimiento en las cooperativas de base de normas estatutarias y reglamentarias comunes.

b) El establecimiento de relaciones asociativas entre las entidades de base.

c) Compromisos de aportación periódica de recursos calculados en función de su respectiva evolución empresarial o cuenta de resultados.

No obstante, el carácter obligatorio de las instrucciones emitidas o de las facultades a ejercer deberá tener soporte en los compromisos generales asumidos ante el grupo y, en cualquier caso, no podrán ser exigibles en caso de que una o varias cooperativas del grupo hayan sido expresamente exoneradas del sometimiento a determinadas normas o compromisos.

3. La aprobación de la incorporación al grupo cooperativo precisará el acuerdo inicial de cada una de las entidades de base conforme a sus propias reglas de competencia y funcionamiento.

4. Los compromisos generales asumidos ante el grupo deberán formalizarse por escrito en los Estatutos de la entidad cabeza de grupo, si es sociedad cooperativa, o mediante otro documento contractual si no lo es, formalizado en escritura pública, que necesariamente deberán incluir la duración del mismo, caso de ser limitada, el procedimiento para su modificación, el procedimiento para la separación de una sociedad cooperativa y las facultades cuyo ejercicio se acuerda atribuir a la entidad cabeza de grupo. La modificación, ampliación o resolución de los compromisos indicados podrá efectuarse, si así se ha establecido, mediante acuerdo del órgano máximo de la entidad cabeza de grupo.

5. La pertenencia a un grupo, y su separación del mismo, se anotarán en la hoja correspondiente a cada sociedad cooperativa en el Registro de Cooperativas.

6. La responsabilidad derivada de las operaciones que realicen las sociedades cooperativas integradas en un grupo directamente con terceros no alcanzará al grupo ni a las demás sociedades cooperativas que lo integran».

15. Una novedad que no debemos eludir es que se requiere del Gobierno Vasco que dote al Departamento competente en materia de 
cooperativismo de los medios personales y materiales necesarios para el adecuado cumplimiento de sus funciones de promoción, difusión, formación, inspección y registral.

Artículo vigesimoprimero. Se da nueva redacción al número 3 del artículo 137 de la Ley 4/1993, de 24 de junio, de Cooperativas de Euskadi, que queda redactado de la manera siguiente:

Artículo 137. 3. El Gobierno Vasco actuará en materia de cooperativismo a través del Departamento al que estuviere adscrita la materia de Trabajo, al que dotará de los medios personales y materiales necesarios para el adecuado cumplimiento de sus funciones de promoción, difusión, formación, inspección y registral, sin perjuicio de las facultades que otros Departamentos tengan reconocidas en relación al cumplimiento de la legislación específica que les corresponde aplicar.

Como en un principio mencionábamos se reconoce la igualdad de trato a los socios trabajadores con respecto al resto de trabajadores por cuenta ajena en las medidas públicas de fomento y consolidación del empleo.

Además, se buscaba una equiparación e igualdad respecto del trato ofrecido a los socios trabajadores en la promoción y consolidación de empleo en la CAV con respecto a los trabajadores por cuenta ajena que parecían absolutamente razonables.

En este sentido, Adrián Celaya recalca la gran sensibilidad demostrada por la Dirección de Economía Social del Gobierno Vasco para dar respuesta a las demandas del sector. Dice textualmente: "Hay que destacar la gran agilidad que ha desplegado la Administración Vasca a la hora de captar y atender los planteamientos originados en su primera fase en la Federación de Cooperativas de Trabajo Asociado y extendidos con posterioridad a las restantes Federaciones».

Artículo vigesimosegundo. Se adiciona una disposición adicional cuarta a la Ley 4/1993, de 24 de junio, de Cooperativas de Euskadi, con la siguiente redacción:

Disposición adicional cuarta. Igualdad de trato en materia de fomento y consolidación de empleo.

Queda prohibida toda discriminación de los socios trabajadores de las cooperativas de trabajo asociado y de los socios de trabajo de otra clase de cooperativas, en la regulación y ejecución de normas sobre incentivos que tengan por objeto la creación o consolidación de empleo, siéndoles de aplicación todas las normas e incentivos es- 
tablecidos para los trabajadores por cuenta ajena por la CAPV en el ejercicio de sus competencias con objeto de crear y consolidar empleos.

16. Otra novedad que incorpora la Ley es: Se acomoda estrictamente a la nueva regulación de la Ley 27/1999, de 16 de julio, en cuanto a su ámbito de regulación, clarificándolo al incorporar el criterio por aquélla regulado, de tal forma que ésta será aplicable a todas las sociedades cooperativas con domicilio social en el territorio de la Comunidad Autónoma del País Vasco que desarrollen con carácter principal su actividad cooperativizada en dicho territorio.

Artículo vigesimotercero. Se da nueva redacción a la disposición final segunda de la Ley 4/1993, de 24 de junio, de Cooperativas de Euskadi, que queda redactada de la manera siguiente:

Disposición final segunda. Ambito de aplicación.

La presente ley es de aplicación a todas las sociedades cooperativas con domicilio social en el territorio de la Comunidad Autónoma del País Vasco que, de conformidad con lo previsto en el artículo 2 A de la Ley 27/1999, de 16 de julio, de Cooperativas, desarrollen con carácter principal su actividad cooperativizada en dicho territorio.

En definitiva, se trata de un conjunto de medidas que tienen una idéntica finalidad de fomentar el cooperativismo en el País Vasco, habida cuenta que ha demostrado ser una fórmula especialmente adecuada para crear puestos de trabajo de calidad, redistribuir la riqueza y hacer posible el acceso de los trabajadores a la propiedad de los medios de producción.

Por último, y debido a razones de técnica normativa, debe realizarse una obligada referencia al alcance de la competencia exclusiva que en materia de cooperativas atribuye el artículo 10.23 del Estatuto de Autonomía a la Comunidad Autónoma del País Vasco, competencia que así mismo ha sido refrendada por el Tribunal Constitucional en su STC $72 / 83$ (F.J. 3. ${ }^{\circ}$ ).

En el ejercicio de esta competencia exclusiva la CAPV ha de respetar, no obstante, los límites que impone el propio artículo 10.23 EAPV, esto es, la legislación general de carácter mercantil, y también aquellos ámbitos competenciales distintos al de cooperativas cuando el contenido de la regulación que se aborda afecte de manera relevante a esos ámbitos. 
Es, por tanto, conveniente realizar las siguientes precisiones respecto a los artículos decimocuarto y vigesimotercero, puesto que las menciones que en los mismos se efectúan de la normativa estatal vienen dadas por el respeto al ámbito competencial estatal y al principio de seguridad jurídica.

El artículo decimocuarto traslada al ámbito autonómico vasco la misma previsión que incorpora el artículo 86.2 de la Ley estatal 27/1999, de 16 de julio, de Cooperativas, equiparando a los socios trabajadores de las cooperativas de trabajo asociado con los trabajadores por cuenta ajena, para extender a aquéllos los derechos y deberes que los trabajadores por cuenta ajena tengan reconocidos en la normativa vigente en relación con el nuevo empresario cuando se produzca la sustitución en una contrata o concesión administrativa por causas no imputables al empresario cesante. Esta equiparación constituye un supuesto de subrogación empresarial que se sitúa, desde una perspectiva material, en el ámbito de la legislación laboral, entendida ésta en el sentido definido por la STC 360/93. En este ámbito material el reparto competencial se encuentra acotado por los artículos 149.1.7 de la CE y 12.2 del EAPV, que no atribuyen a la CAPV competencia normativa alguna en esta materia. Es por ello por lo que en este artículo duodécimo se realiza una reproducción en su integridad del artículo 86.2 de la Ley estatal 27/1999, de 16 de julio, de Cooperativas.

Así mismo, es preciso referirse a la nueva definición del ámbito de aplicación de la ley que efectúa el artículo vigesimotercero. La Ley estatal 27/1999, de 16 de julio, de Cooperativas, ha excluido de su ámbito de aplicación a aquellas cooperativas que desarrollen principalmente su actividad cooperativizada en el territorio de una Comunidad Autónoma. Es por ello por lo que, conforme a lo dispuesto en el artículo 2 A de la citada Ley 27/1999, hay que entender que las sociedades cooperativas que desarrollen principalmente su actividad cooperativizada en el ámbito territorial de la CAPV se rigen por la ley vasca de Cooperativas. Por esta razón en el artículo vigesimoprimero de esta ley se reitera la previsión establecida en el artículo 2 A de la ley estatal.

El articulado de la ley se completa con las correspondientes disposiciones de cierre, entre las que cabe destacar su disposición adicional única $\mathbf{s}_{\mathbf{s}}$ en la que se insta al Gobierno a promover la coordinación entre los distintos Registros con la finalidad de simplificar el sistema de cer- 
tificación de denominación no coincidente y de reforzar la seguridad jurídica respecto a la denominación societaria de las empresas, cualquiera que sea su forma jurídica, en el marco de la unidad de mercado. Así pues, cuando se lleven a efecto los mecanismos de coordinación que se acuerden, perderá su vigencia el sistema de certificación previsto en el artículo 12.2 f) de la Ley 4/1993, de 24 de junio, de Cooperativas de Euskadi.

Disposición adicional única.

El Gobierno promoverá la coordinación del Registro de Cooperativas de Euskadi con el Registro de Cooperativas estatal y el Registro Mercantil Central para sustituir el sistema previsto en el artículo 12.2.f) de la Ley 4/1993, de 24 de junio, de Cooperativas de Euskadi, por otro de certificación única de denominación no coincidente.

Disposición transitoria única.

Las participaciones especiales cuyo plazo de vencimiento no haya expirado mantendrán el régimen establecido en su emisión.

Disposición final única.

La presente ley entrará en vigor el día siguiente al de su publicación en el Boletín Oficial del País Vasco.

\section{III.2. Otras novedades}

Artículo décimo. Se da nueva redacción a la letra b) del número 2 del artículo 66 de la Ley 4/1993, de 24 de junio, de Cooperativas de Euskadi, que queda redactado de la manera siguiente:

Artículo 66.b) Los intereses debidos por las aportaciones al capital social regulado en el artículo 57 de esta ley y por las prestaciones y financiaciones no integradas en el capital social.

Artículo undécimo. Se da nueva redacción al número 4 del artículo 99.4 de la Ley 4/1993, de 24 de junio, de Cooperativas de Euskadi, que quedaría redactado de la siguiente manera:

Artículo 99.4. El número de horas/año realizadas por trabajadores con contrato de trabajo por cuenta ajena no podrá ser superior al 25 por ciento del total de horas/año de trabajo realizadas por los socios trabajadores. Si las necesidades objetivas de la empresa obligaran a superar este porcentaje, ello será válido para un período que no exceda de tres meses; para superar dicho plazo deberá solicitarse autorización motivada al Departamento al que estuviere ads- 
crita la materia de Trabajo, que ha de resolver en un plazo de quince días y en caso de silencio se entenderá concedida la autorización.

No se computarán en este porcentaje:

a) Las horas/año de trabajo realizadas en centros y unidades de trabajo de carácter subordinado o accesorio.

Se entenderá, en todo caso, como trabajo prestado en centro de trabajo subordinado o accesorio el prestado por los trabajadores por cuenta ajena que contraten las cooperativas para prestar servicios de duración determinada en los locales del cliente o su beneficiario y para la Administración pública. También aquellas actividades que deba realizar la cooperativa en obras, montajes o actividades auxiliares, siempre que éstas no constituyan el objeto social principal de la cooperativa y que se presten fuera de los locales de la cooperativa por exigencias propias de la actividad, y siempre que la relación con la cooperativa no tenga carácter claramente estable y de duración indefinida.

b) El trabajo realizado por los trabajadores por cuenta ajena integrados en las cooperativas por subrogación legal, así como por aquellos que se incorporen en actividades sometidas a estas subrogaciones.

c) El trabajo desempeñado por trabajadores que sustituyan a socios trabajadores o asalariados en situación de excedencia e incapacidad temporal, baja por maternidad, adopción o acogimiento.

d) El trabajo desempeñado por trabajadores que se negasen explícitamente a ser socios trabajadores.

No obstante lo dispuesto en este número, las cooperativas con menos de ocho socios trabajadores podrán emplear hasta un máximo de dos trabajadores con contrato de trabajo por cuenta ajena.

Artículo decimotercero. Se suprime el número 9 del artículo 99 de la Ley 4/1993, de 24 de junio, de Cooperativas de Euskadi.

Artículo decimosexto. Se da nueva redacción a los números 2 y 3 del artículo 129 de la Ley 4/1993, de 24 de junio, de Cooperativas de Euskadi, que quedan redactados de la manera siguiente:

Artículo 129. 2. La admisión de cualquier socio persona jurídica requerirá acuerdo favorable del Consejo Rector por mayoría de al menos dos tercios de los votos presentes y representados, salvo previsión de otra mayoría en los Estatutos; éstos también podrán regular períodos de vinculación provisional o a prueba de hasta dos años, y atribuir la decisión sobre la admisión a la Asamblea General. 
3. El socio persona jurídica que pretenda darse de baja habrá de cursar, salvo exoneración del Consejo Rector, un preaviso de al menos un año, y antes de su efectiva separación estará obligado a cumplir las obligaciones contraídas con la cooperativa de segundo o ulterior grado o a resarcirla económicamente, si así lo decide el Consejo Rector de ésta. Asimismo, salvo previsión estatutaria en contra, la entidad separada deberá continuar desarrollando, durante un plazo no inferior a dos años, los compromisos que hubiera asumido con anterioridad a la fecha de la baja.

Artículo decimoséptimo. Se da nueva redacción al número 1 del artículo 130 de la Ley 4/1993, de 24 de junio, de Cooperativas de Euskadi, que queda redactado de la manera siguiente:

Artículo 130.1. Las aportaciones obligatorias al capital social de una cooperativa de segundo o ulterior grado se realizarán en función de la actividad cooperativa comprometida con aquélla por cada socio, conforme establezcan los Estatutos, bien en razón del número de socios o bien conforme a los criterios establecidos para las cooperativas de primer grado en el artículo 58.1 de esta ley.

Artículo decimoctavo. Se da nueva redacción al artículo 131 de la Ley 4/1993, de 24 de junio, de Cooperativas de Euskadi, que queda redactado de la manera siguiente:

Artículo 131. Estructura orgánica y derecho de voto.

1. La Asamblea General estará formada por un número de representantes de los socios personas jurídicas proporcional al derecho de voto de cada entidad socia, pudiendo fijarse en los Estatutos Sociales límites máximos y mínimos, y, en su caso, por los representantes de los socios de trabajo. A su vez, el derecho de voto de las entidades será proporcional a la participación en la actividad cooperativa o al número de socios. El número de votos de una entidad que no sea sociedad cooperativa no podrá ser superior a un tercio de los votos sociales, salvo que hubiese menos de cuatro socios.

2. Las cooperativas de segundo o ulterior grado serán administradas por un Consejo Rector que tendrá, salvo previsión estatutaria en contra, un número máximo de quince miembros, y en él estarán representadas, directa o indirectamente, todas las entidades socias. En el caso de que el número de entidades socias supere el máximo legal o estatutario de miembros, las que tengan menor número de votos podrán agruparse a efectos de designar sus representantes, observando las previsiones estatutarias o reglamentarias internas al respecto.

El derecho de voto en el seno del Consejo podrá ser proporcional a la actividad cooperativa o al número de socios de la entidad o 
entidades a las que representan los consejeros, con el límite señalado para la Asamblea General.

Los Estatutos podrán prever que hasta un tercio de los miembros del Consejo Rector puedan ser designados, por los rectores electos, entre personas capacitadas que podrán ser o no miembros de alguna cooperativa del grupo.

\section{EL REGIMEN JURÍDICO DE LOS SOCIOS}

\section{El socio}

En las cooperativas de primer grado, el socio «es, no sólo el principal elemento creador y mantenedor de la cooperativa, sino, además, el destinatario y persistente protagonista de la misma. Sin socios y sin la continuada participación de éstos en la cooperativa, no hay cooperativa ni vida cooperativa».

En palabras de J. SANZ JARQUE: «para que haya efectivamente cooperativa y movimiento cooperativo, que deben ir unidos, con independencia al derecho a constituirse en cooperativa, como manifestación del derecho fundamental de asociación y del derecho a asociarse en una cooperativa, en virtud del consistencial principio cooperativo de puesta abierta o libre adhesión, se requiere de modo general: una capacidad especial para constituir cada cooperativa o para ingresar en ella, esto es para ser socio; una continuada participación societarioempresarial del socio en la cooperativa; un continuado y particular modo cooperativo de ser y de estar y de participar en la misma y una continuada y peculiar dinámica de los socios, entre sí recíprocamente, de éstos con la cooperativa, de la cooperativa con los socios, y de una y otra con terceros, con los acreedores y con la sociedad o comunidad política en la que se ubica, inserta y desenvuelve la cooperativa».

Como regla general, cualquier persona, sea física o jurídica, pública o privada, puede ser socia de una cooperativa. No obstante, la LV establece una serie de salvedades (artículo 19. I).

Igualmente, pueden ser socios, los entes públicos con personalidad jurídica cuando el objeto de la cooperativa sea prestar servicios o realizar actividades que no supongan ni requieran el ejercicio de la autoridad pública y estén relacionadas con las a ellos encomendadas (artículo 19.3). 


\section{Número de socios}

Para la constitución de una cooperativa de primer grado se exigen tres socios de la clase de cooperativa que se constituye, mientras para las de segundo o ulterior grado basta con un mínimo de dos sociedades cooperativas (artículo 19.1).

Habida cuenta de que su objetivo era favorecer la creación de nuevas Cooperativas, parecía razonable que el número mínimo de socios, cinco, se redujera ya que esa era la tendencia en el derecho cooperativo del Estado, y no conculca dogmática cooperativa alguna.

Además, había datos suficientes, a raíz de los estudios realizados por la Federación, que mostraban que la inmensa mayoría de las iniciativas empresariales, en general, no nacían con muchos socios (dos o tres), y con ello se facilita emprender cooperativamente. Además, se buscaba una equiparación e igualdad respecto del trato ofrecido a los socios trabajadores en la promoción y consolidación de empleo en la C.A.V. con respecto a los trabajadores por cuenta ajena que parecían absolutamente razonables.

Igualmente se constataba que el número de nuevas promociones de Cooperativas había tenido una curva ascendente desde 1985 hasta 1993, mientras que a partir de ese año la curva coge un derrotero descendente, siendo cada vez más acusado. Con estos antecedentes, existía desde hace tiempo en el Movimiento Cooperativo una sensibilidad para que se redujera el número mínimo de socios fundadores. La Ley 1/2000 recoge esta demanda y reduce el número mínimo de socios fundadores de cinco a tres.

Como dato a destacar es que en opinión de una parte de la doctrina, existía una conciencia de que había una serie de cuestiones legislativas que eran claves a la hora de que se crearan más Cooperativas.

Entre ellas, la disminución del número mínimo para la constitución de una Cooperativa. En Cataluña ya se habían percatado de este handicap y ya habían empezado a tomar medidas con buenos resultados. A partir de la constatación del sector y de la sensibilidad demostrada por el Gobierno Vasco, se produjo la reforma y la disminución del número mínimo de socios fundadores de cinco a tres.

El R.R.C., elimina del cómputo de socios mínimo necesario para la constitución de una cooperativa, a todos los socios no cooperadores (artículo 39.2). 
La capacidad para constituir la cooperativa, es la exigida por la legislación común o foral aplicable.

\section{Clases de socios}

Los socios pueden ser clasificados de diferentes maneras atendiendo a diversos criterios. Así pueden ser: personas físicas o jurídicas; públicas o privadas; activos o usuarios, inactivos o no usuarios, colaboradores, de duración indefinida o determinada, etc...

\section{III.1. Socios activos o usuarios}

Aún cuando no están expresamente recogidos en la LV, debe entenderse por tales a aquellos que pueden realizar plenamente el objeto social cooperativo o, dicho de otra forma, los que realizan la actividad cooperativa o utilizan los servicios prestados por la sociedad cooperativa.

Son denominados socios trabajadores (artículo 99.2) en las cooperativas de trabajo asociado.

\section{III.2. Socios colaboradores}

Aquellas personas físicas o jurídicas, públicas o privadas, que, sin poder realizar plenamente el objeto social cooperativo, pueden colaborar en la consecución del mismo (artículo 19.2).

Esto es, por un lado los de jerarquía normativa, en cuanto que el artículo 39.2 RRC eliminaba, del cómputo de socios mínimo necesario para la constitución de una cooperativa, a todos los socios no cooperadores y, a su vez, la Orden de 11 de octubre de 1994, del Consejero de Trabajo y Seguridad Social, sobre la aplicación del artículo 39.2 RRC, establece su no aplicabilidad para las cooperativas ya constituidas, al diferenciar la constitución de la modificación de estatutos que suponía la adaptación a la Ley. Esto es, la Orden modificaba el Decreto que restringía la Ley.

Por otro lado, se atiende a la realidad cooperativa vasca, constituida por pequeñas cooperativas que no siempre podían permitirse cinco socios (por ejemplo, en las de trabajo asociado en las que suponía crear cinco empleos).

Además, con la reforma se devuelve competitividad jurídica a la fórmula cooperativa vasca frente a las sociedades laborales y se unifi- 
ca el número mínimo de socios con la Ley vasca (artículo 8 Ley 27/1999), si bien es cierto que en ésta no se plantea la exigencia de su referencia a la clase de cooperativa que se constituye.

Los derechos y obligaciones de estos socios se deben regular en estatutos sociales $y$, en lo no previsto por éstos, mediante pacto entre las partes.

Salvo que sean sociedades cooperativas, no pueden ser titulares de más de un tercio de los votos, ni en el asamblea general ni en el consejo rector. Con esta medida, igual que con otras similares que se establecen para otros tipos de socios, se pretende que la mayoría de los votos pertenezca a socios activos o usuarios, esto es, a los que vienen a desarrollar la actividad cooperativa.

\section{III.3. Socios de trabajo}

Las cooperativas de primer grado que no sean de trabajo asociado y las de segundo o ulterior grado pueden prever, en sus estatutos, los requisitos que deben cumplir los trabajadores para adquirir la condición de socios de trabajo. Su actividad cooperativa consistirá en al prestación de su trabajo personal en la cooperativa (artículo 21.l).

Se les aplican las normas establecidas para los socios trabajadores (artículo 21.1) de las cooperativas de trabajo asociado, con las siguientes salvedades:

Los criterios para su participación, equitativa y ponderada, en la cooperativa deben ser fijados en estatutos (artículo 21.3).

El período de prueba, que puede ser previsto en estatutos, no procede si el nuevo socio llevase en la cooperativa, como trabajador por cuenta ajena, el tiempo que corresponda al periodo de prueba. En caso de que procediese período de prueba y la relación fuese resuelta unilateralmente por cualquiera de las partes, la relación jurídico laboral anterior se entiende renovada en las condiciones existentes al inicio de dicha fase de prueba, salvo que se hubiese extinguido con anterioridad a dicho período de prueba (artículo 21.4).

\section{III.4. Socios inactivos o no usuarios}

Los Estatutos de la cooperativa pueden prever que los socios que por cualquier causa justificada (y con una antigüedad mínima que en 
ellos se determine), dejen de utilizar los servicios prestados por la misma o de realizar la actividad cooperativa (esto es, dejen de ser socios activos o usuarios), puedan seguir siendo socios (artículo 30. I).

Sus derechos y obligaciones deben ser igualmente establecidos en estatutos, si bien el conjunto de sus votos, no puede ser superior a la quinta parte del total de votos sociales (artículo 30.2).

Cuando la inactividad tenga por origen la jubilación del socio, se permite que el interés con que se retribuya su aportación al capital social, sea superior al de los socios en activo, con el único límite del tipo de interés legal más seis puntos (artículo 30.3).

Se pretende así que los socios que se jubilen no tengan que causar necesariamente baja en la cooperativa, teniendo ésta que reembolsar unas aportaciones que tras una vida como socio pueden ser elevadas y permitiendo que se retribuyan de una forma más interesante que a otros socios. Se evita igualmente, que el socio deba dejar de serlo, pudiendo aún mantener el vínculo societario.

\section{III.5. Socios de duración determinada}

Una de las novedades de la Ley, fue la introducción de la figura del socio de duración determinada, «lo que, además de responder a las necesidades constatadas en la práctica, contribuirá sin duda a preservar la homogeneidad jurídica entre los sujetos que participan en la actividad de la empresa y refleja una mayor coherencia ideológica que la derivada de vínculos transitorios de carácter extracooperativo, carentes de implicación asociativa» (E.M.).

Sus derechos y obligaciones deben ser equivalentes a los de los demás socios y regularse en los Estatutos.

El conjunto de estos socios no puede superar, como regla general, la quinta parte de los socios de carácter indefinido de la clase de que se trate, ni de los votos de estos últimos en la asamblea general.

Como excepción, se permite en las cooperativas de trabajo asociado o en las que, siendo de otra clase, tengan socios de trabajo, superar dichas proporciones siempre que el número de horas/año de trabajo realizadas en conjunto por los socios de duración determinada y los trabajadores por cuenta ajena no llegue al $50 \%$ del total de horas/año realizadas por los socios trabajadores o de trabajo de carácter indefinido. 
Por último, se otorga a los socios trabajadores o de trabajo, titulares de contratos societarios de duración determinada que acumulen un período de tres años en dicha situación, la opción de adquirir la condición de socio de duración indefinida, y si dicho período alcanza cinco años, se prevé la adquisición en todo caso, siempre que cumplan los demás requisitos estatutariamente establecidos para los socios de duración indefinida.

\section{La admisión}

Los estatutos deben fijar los requisitos necesarios para la adquisición de la condición de socio, respetando los mínimos establecidos por la Ley de Cooperativas (artículo 20. I).

La solicitud debe formularse por escrito a los administradores, que deben resolver en un plazo máximo de sesenta días desde su recepción. Se prevé el silencio positivo, esto es, si transcurre el plazo sin resolución expresa se entiende aprobada la solicitud de admisión (artículo 20.3).

No cabe aceptar o denegar la admisión por causas que supongan una discriminación arbitraria o ilícita, en relación con el objeto social (artículo 20.2).

A diferencia de la Ley del 82, la Ley de 1993 desarrolla tanto el recurso del aspirante por la denegación de admisión como la posible reclamación de los socios contra el acuerdo de admisión de un nuevo cooperativista, así como el momento en el que adquiere la condición de socio.

La denegación debe ser motivada (artículo 20.3), cabiendo recurso ante el comité de recursos y, en su defecto, ante la asamblea general. Se fija el plazo de recurso en veinte días desde su notificación.

El recurso debe resolverse en treinta días, si existe comité de recursos, o en la primera asamblea general que se celebre mediante votación secreta. El interesado debe ser, en ambos supuestos, escuchado preceptivamente (artículo 20.4).

Contra el acuerdo de admisión cabe igualmente recurso ante los mismos órganos, por parte de un número de socios determinado en estatutos y en el plazo que éstos fijen. Los estatutos no pueden señalar un plazo superior a veinte días desde la notificación del acuerdo (artículo 20.5.). 
El recurso debe ser resuelto en los mismos plazos y con la misma preceptiva audiencia que en el caso de denegación de admisión y mediante votación secreta.

La adquisición de la condición de socio, queda en suspenso hasta que transcurra el plazo para recurrir la admisión o, en caso de recurso contra la misma, hasta que el mismo sea resuelto por el órgano competente.

Igualmente, se exige para adquirir tal condición, que se desembolse la parte de la aportación obligatoria inicial establecida en estatutos (mínimo, el veinticinco por ciento) y la cuota de ingreso (artículos 58 y 65.2).

\section{Obligaciones de los socios}

La Ley vasca de 1993, mantiene la relación de obligaciones ya prevista en la de 1982, explicitando la de guardar secreto para no lesionar los intereses sociales.

Así, los socios están obligados (artículo 22) a:

- Asistir a las reuniones de las asambleas generales y de los demás órganos a los que se les convoque.

- Aceptar los cargos para los que sean elegidos, salvo que medie una justa causa de excusa.

- Participar en las actividades que constituyen el objeto de la cooperativa según los módulos o normas mínimas que señalen los estatutos. No obstante, cuando exista causa justificada, los administradores pueden liberar al socio de esta obligación en la medida que proceda.

- No realizar actividades competitivas con el objeto social que desarrolla la cooperativa, ni colaborar con quien las realice, salvo autorización expresa de los administradores.

- Guardar secreto sobre las actividades y datos de la cooperativa, si su divulgación puede perjudicar los intereses sociales.

- Desembolsar sus aportaciones al capital social, en las condiciones previstas.

- Asumir la imputación de pérdidas en la cuantía acordada por la asamblea general.

- Cumplir los demás deberes que resulten de las normas legales y estatutarias, así como de los derivados de acuerdos válidamente adoptados por los órganos de la cooperativa. 


\section{Derechos de los socios}

Contrapartida de las anteriores obligaciones y dada la condición de socios, la Ley señala una serie de derechos de los socios. Dichos derechos, al igual que las obligaciones, pueden ser patrimoniales y políticos .

En relación a la anterior Ley de 1982, la actual recoge el derecho a formular propuestas y se regula de manera más amplia el derecho de información, sus límites y el recurso contra su denegación motivada.

\section{VI.1. Derecho y ejercicio:}

Los socios tienen derecho (artículo 23) a:

- Elegir y ser elegidos para los cargos sociales de la cooperativa 4 .

- Formular propuestas y participar con voz y voto en la adopción de todos los acuerdos de la asamblea general y de los demás órganos de los que formen parte.

- Participar, sin discriminación, en todas las actividades de la cooperativa.

- Recibir la información necesaria para el ejercicio de sus derechos y el cumplimiento de sus obligaciones.

- La actualización y devolución, cuando proceda, de las aportaciones al capital social, así como a percibir, en su caso, intereses por las mismas.

- Al retorno cooperativo, en su caso ${ }^{5}$.

- Los demás que resulten de las leyes y de los estatutos. Así, en la propia Ley se enumeran los siguientes:

- El derecho a separarse de la cooperativa en ciertos supuestos y con ciertos requisitos como el acuerdo de cambio de clase de cooperativa (artículo 74.4), la modificación sustancial del objeto

4 Este derecho vendría a responder a un «principio de gestión democrática» ya que, en palabras del profesor Divar (La metamorfosis del capital. Bases de la empresa futura): «De la misma manera que la democracia política implica un abanico de derechos mínimos, la democracia societaria supone también una pluralidad de resultancias jurídicas, ya que el principio se extiende a todo el régimen jurídico de las sociedades cooperativas».

5 «El sistema cooperativo, como populista y democrático, implica una formulación empresarial particiada por todos sus agentes, y la última consecuencia de esa participación es la del dividendo (y la más definitiva económicamente)». DIVAR J. La metamorfosis del capital. Bases de la empresa futura. 
social (artículo 74.4), la fusión (artículo 80) y la transformación (artículo 85. I).

-El derecho de los socios trabajadores de las cooperativas de trabajo asociado a percibir periódicamente, en plazo no superior a un mes, anticipos laborales en cuantía no inferior al salario mínimo interprofesional en cómputo anual (artículo 99.6).

- Otros derechos específicos en cada clase de cooperativa.

- El derecho de información.

El ejercicio de los derechos debe realizarse conforme a las normas legales y estatutarias y con los acuerdos válidamente adoptados por los órganos de la cooperativa.

\section{VI.2. El derecho de información}

Para J. DIvar ${ }^{6}$ supone el reconocimiento de la base sustancial para el ejercicio de toda potestad jurídico-empresarial, en cuanto que lógicamente no es factible la realización responsable de ningún derecho de resultancia económica sin un previo conocimiento exacto y en profundidad de las circunstancias

La Ley reconoce a los socios un derecho de información en los términos previstos en la misma, en los estatutos o en los acuerdos de la asamblea general. Se permite que la asamblea general (en estatutos o por simple acuerdo), establezca los cauces que crea convenientes para facilitar y hacer efectivo este derecho de los socios (artículo 24. 1).

Expresamente, la Ley enumera los siguientes:

- Solicitar una copia de los estatutos sociales de la cooperativa y, en su caso, del reglamento de régimen interno (artículo 24.2).

- Examinar el libro registro de socios de la cooperativa y el libro de actas de la asamblea general (artículo 24.2).

- Obtener de los administradores copia certificada del acta y de los acuerdos adoptados en la asamblea general, y certificación de las inscripciones en el libro registro de socios, previa solicitud motivada (artículo 24.2). Se exige, así, para el ejercicio de este derecho, que se motive para qué se quiere el certificado solicitado.

- Solicitar copia certificada de los acuerdos de los administradores que le afecten individualmente (artículo 24.2).

6 Divar, J., La metamorfosis del capital. Bases de la empresa futura. 
- Ser informado por los administradores, y en el plazo máximo de un mes desde su solicitud, sobre su situación económica en relación con la cooperativa (artículo 24.2).

- Solicitar por escrito a los administradores, las aclaraciones o informes que considere necesarios sobre cualquier aspecto del funcionamiento o de los resultados de la cooperativa (artículo 24.3). Este derecho debe ser satisfecho en la primera asamblea general que se celebre, pasados quince días desde la presentación del escrito (artículo 24.3).

- Tener a su disposición en el domicilio de la cooperativa (para que puedan ser examinados por los mismos durante el plazo de convocatoria de la asamblea general) los documentos que reflejen las cuentas anuales, la propuesta de aplicación de resultados y, en su caso, el informe de gestión realizado por la comisión de vigilancia cuando en dicha Asamblea, de acuerdo con el orden del día, haya de deliberarse sobre las cuentas del ejercicio o de cualquier propuesta económica (artículo 24.4).

- Solicitar por escrito, desde la convocatoria y al menos con cinco días de antelación a la celebración de la asamblea, las explicaciones y aclaraciones referidas a la documentación económica indicada en la letra anterior, para que sean respondidas en el acto de la asamblea (artículo 24.4).

- Representando al menos el diez por ciento del total de los votos sociales, solicitar por escrito en todo momento la información que consideren necesaria. Los administradores deben proporcionarla por escrito en un plazo máximo de treinta días (artículo 24.5).

- Ser informados (ellos o los órganos que los representen) por los administradores, trimestralmente al menos y por el cauce que se estime conveniente, de las principales variables socio-económicas de las cooperativas (artículo 24.6).

\section{VI.3. Límites y garantías del derecho de información}

Los administradores solamente pueden denegar la información cuando la solicitud sea temeraria u obstruccionista, o su atención pusiera en grave peligro los intereses legítimos de la cooperativa. Se exige que en la denegación se indiquen los motivos de la misma.

No obstante, ésta no cabrá cuando la información haya de ser proporcionada en el acto de la asamblea general y la solicitud sea 
apoyada por más de la mitad presentes y representados y en los demás supuestos cuando, a consecuencia de recursos interpuestos contra la denegación por los solicitantes, así lo acuerde el comité de recursos o, en su defecto, la asamblea.

En todo caso, el acuerdo denegatorio de los administradores, puede ser impugnado, conforme al procedimiento previsto a tal fin en la Ley (artículo 25. 1).

Además, los estatutos, para evitar arbitrariedades y perjuicios tanto en la solicitud como en la aportación o la denegación de información, pueden establecer un sistema de garantías que tenga en cuenta las particularidades de la cooperativa y la efectiva situación del socio tanto en la actividad cooperativa como en sus derechos y obligaciones (artículo 25.2).

El incumplimiento de estas garantías estatutarias puede ser recurrido por los solicitantes conforme al procedimiento del artículo 2.166 de la Ley de Enjuiciamiento Civil (artículo 25.1). Esto es, solicitando por escrito al Juez, lo denegado por los administradores, para que este ordene que se le ponga de manifiesto en el acto.

\section{Baja de los socios}

Derecho consustancial derivado del principio de «puerta abierta»; puede ser además una obligación, ocasionada por la pérdida de los requisitos necesarios para serlo (baja obligatoria), o una sanción (expulsión).

\section{VII.1. Tipos de bajas}

Las bajas de los socios pueden ser voluntarias (artículo 26) u obligatorias (artículo 27). Será voluntaria la solicitada por el socio con tal carácter ${ }^{7}$. Se exige sea escrita y puede producirse en todo momento. No obstante, cabe establecer en estatutos la necesidad de avisar por escrito a los administradores de la intención de causar baja, con una

7 «El principio voluntarista supone también la posibilidad de baja del socio cooperativo sin necesidad de sujetarse a causalidad alguna, es decir, sin sometimiento a la existencia razones de Derechos que legitimen su acto de voluntad» (DIvAR J., La metamorfosis del capital. Bases de la empresa futura). 
antelación que no puede ser fijada en más de seis meses para las personas físicas y a un año para las jurídicas (artículo 26. I).

Asimismo, cabe que los estatutos exijan permanecer en la sociedad hasta el final del ejercicio económico o por un tiempo mínimo desde su ingreso en la cooperativa, que no puede ser superior a cinco años (artículo 26.3).

Será obligatoria la que se produce cuando los socios pierden los requisitos exigidos en los estatutos o en la Ley 4/1993 para serlo (artículo 27. I).

A diferencia de la voluntaria, no es necesario que sea solicitada por el afectado, siendo acordada por los administradores, sea porque ellos mismos detecten la situación o porque así se lo solicite cualquier otro socio o el propio interesado. Se exige, en cualquier caso, la audiencia del afectado (artículo 27.2).

\section{VII.2. Calificación}

Las bajas, voluntarias $u$ obligatorias, pueden ser justificadas o no justificadas. Tienen la consideración de bajas voluntarias no justificadas: el incumplimiento del plazo de preaviso y las bajas que dentro de los plazos mínimos de permanencia se produjeran.

No obstante, los administradores de la cooperativa, atendiendo a las circunstancias del caso, pueden acordar lo contrario.

La calificación es independiente de la posible exigencia al socio del cumplimiento de las actividades y servicios cooperativos a los que venía obligado y, en su caso, de la correspondiente indemnización de daño y perjuicios (artículo 26.4).

Además de lo antes indicado, serán bajas voluntarias no justificadas, aquellas en que el socio vaya a realizar actividades competitivas con las de la cooperativa y cualquier otro supuesto previsto en los estatutos sociales (artículo 26.5).

Por el contrario, serán siempre bajas voluntarias justificadas, las solicitadas por los socios que hubiesen votado en contra o que, no habiendo asistido a la asamblea general expresen su disconformidad con los siguientes acuerdos adoptados en la misma: prórroga de la actividad de la cooperativa, su fusión o escisión, el cambio de clase o la alteración sustancial del objeto social de aquélla, la exigencia de nuevas 
aportaciones obligatorias al capital y la transformación de la cooperativa (artículo 26.6).

Serán bajas obligatorias justificadas aquellas en las que la pérdida de los requisitos para ser socio, no sea consecuencia de la voluntad del socio de incumplir sus obligaciones con la cooperativa o de beneficiarse indebidamente con la misma.

En caso de que los administradores la califiquen (en base a lo anterior) como no justificada, cabrá exigir, conforme a los estatutos, la permanencia de los socios hasta el final del ejercicio económico o por un tiempo mínimo que no podrá ser superior a cinco años, así como el cumplimiento de las actividades y servicios cooperativos en los términos en que venía obligado y, en su caso, la correspondiente indemnización de daños y perjuicios (artículos 27.4 y 26.3 y 4).

\section{VII.3. Recursos}

El socio que no esté de acuerdo con la decisión de los administradores sobre la calificación o efectos, tanto de las bajas voluntarias como de las obligatorias, puede recurrir:

- Internamente, ante el comité de recursos, o ante la asamblea general si no existe aquél, en un plazo de treinta días desde que recibió la notificación del acuerdo. Si existe comité de recursos, el mismo debe resolver, tras oír al interesado, en menos de tres meses desde que dicho recurso fue presentado; si no resuelve y notifica en dicho plazo, se entiende que el recurso ha sido estimado. Si no existe comité de recursos, será la primera asamblea general que se convoque tras su interposición la encargada de resolverlo. A tal efecto, se incluirá en su orden del día y, previa audiencia del interesado, se resolverá en votación secreta (artículos 27.5 y 28.2).

- Externamente, cabe impugnar el acuerdo de expulsión, una vez ratificado por el comité de recursos o la asamblea general, en el plazo de dos meses desde su notificación, por el procedimiento previsto para la impugnación de acuerdos de la asamblea general (artículo 28.4).

El acuerdo de los administradores relativo a las bajas obligatorias, será ejecutivo desde que sea notificada la ratificación del comité de recursos o, en su defecto, de la asamblea general, o haya transcurrido el plazo para recurrir ante los mismos. Cabe, sin embargo, que los ad- 
ministradores suspendan cautelarmente los derechos y obligaciones del socio hasta que el acuerdo sea ejecutivo, siempre que lo prevean los estatutos, los cuales deben determinar el alcance de la suspensión. En cualquier caso, el socio conserva su derecho de voto en la asamblea general, mientras el acuerdo no sea ejecutivo (artículo 27.3).

\section{Normas de disciplina social}

\section{VIII.1. Tipificación}

Las normas de disciplina social, deben ser recogidas en los estatutos de cada cooperativa.

Sólo cabe sancionar a los socios por faltas previamente tipificadas en los estatutos o, si se califican como leves, en el reglamento de régimen interno (artículo 29. I).

Las faltas pueden dividirse en leves, graves y muy graves.

\section{VIII.2. Tipos de sanción}

Las sanciones deben estar fijadas, para cada clase de falta, en los estatutos y pueden ser de amonestación, económicas, de suspensión de derechos sociales, o de expulsión (artículo 29. I).

El alcance de la suspensión de los derechos del socio, debe ser determinado necesariamente por los estatutos sociales (artículo 29.4).

\section{VIII.3. Prescripción}

Las infracciones leves prescriben al mes, las graves a los dos meses, y las muy graves a los tres meses.

El plazo de prescripción, empieza a contar el día en que los administradores tienen conocimiento de la comisión de la infracción y, en cualquier caso, doce meses después de haber sido cometida. Este último plazo, es una garantía que aporta seguridad jurídica, por cuanto que por un lado, en ciertos supuestos es muy difícil acreditar cuándo tienen conocimiento los administradores de la infracción y, por otro lado, el socio no puede quedar sujeto a la amenaza de posibles sanciones por antiguas infracciones. 
El plazo se interrumpe, al incoarse el procedimiento sancionador y corre de nuevo, si en el plazo de cuatro meses no se dicta ni se notifica la resolución (artículo 29.2). Dada la literalidad de la expresión, parece que el hecho de dictar la resolución sirve para volver a interrumpir el plazo, disponiéndose de otros cuatro meses para notificar, sin que se inicie de nuevo el cómputo de la prescripción.

Esta interpretación, da un plazo excesivamente largo a los administradores, además de introducir un problema de prueba para el socio que solicite la prescripción dado que el acuerdo es un acto interno, pudiendo quedar su prueba reducida, en caso de administrador único, a un problema entre la palabra del administrador que dice tomó el acuerdo y del socio que lo niegue.

\section{VIII.4. Procedimiento y recursos}

Los estatutos deben fijar el procedimiento sancionador y los recursos correspondientes, respetándose, en cualquier caso, una serie de normas mínimas, que viene a señalar la propia Ley vasca de cooperativas.

Dichos mínimos son:

- Los administradores son los competentes para sancionar, sin que quepa delegación alguna.

- Debe darse audiencia previa al interesado.

- Las sanciones por faltas graves o muy graves son recurribles ante el comité de recursos o, en su defecto, ante la asamblea general, en el plazo de treinta días desde que la sanción fue notificada.

- El acuerdo sancionador puede ser impugnado, conforme al procedimiento previsto para la impugnación de acuerdos de los administradores.

- La ratificación del acuerdo sancionador, por el comité de recursos o por la asamblea general, puede ser impugnada, en el plazo de un mes desde la notificación, por el trámite procesal previsto para la impugnación de acuerdos de la asamblea general (artículo 29.3).

\section{VIII.5. La expulsión}

La expulsión es la sanción máxima aplicable a un socio. Exige el acuerdo de los administradores por falta muy grave tipificada en los 
estatutos, un expediente instruido al efecto y la audiencia del interesado (artículo 28. I).

Contra el acuerdo de expulsión, caben los recursos internos y externos indicados al referirnos a las bajas voluntaria y obligatoria (artículo 28.2 y 4).

El acuerdo es ejecutivo desde que se notifica la ratificación del comité de recursos 0 , en su defecto, de la asamblea general, o desde que transcurre el plazo para recurrir ante los mismos, sin que se haya presentado recurso alguno (artículo 28.3).

\section{LA ASAMBLEA GENERAL}

\section{Concepto y competencias}

La asamblea general es el órgano supremo de expresión de la voluntad social. La ley la define como «la reunión de los socios, constituida para deliberar y tomar acuerdos en las materias propias de su competencia» (artículo 31.1).

De la definición legal se deduce que no puede existir asamblea general sin la presencia física simultánea de una pluralidad de socios, que para serlo verdaderamente deben ser observadas las reglas de la convocatoria y constitución previstas en la Ley y que ha de dedicarse a deliberar y tomar acuerdos en las materias propias de su competencia. La referencia a «las materias propias de su competencia» expresa claramente que, siendo órgano soberano, la asamblea general no está dotada de poderes omnímodos que le permitan decidir válidamente en toda clase de asuntos y cuestiones.

Lo anterior pone de manifiesto la importancia de delimitar el ámbito de competencias de la asamblea general. En este punto, la Ley, siguiendo las pautas del moderno Derecho de sociedades y para evitar la posibilidad de configurar un modelo de gestión asamblearia de la cooperativa, no permite que la asamblea pueda tomar acuerdos obligatorios en materia de competencia exclusiva de otro órgano social.

Para precisar las competencias de la asamblea, por una parte, enumera determinados acuerdos cuya adopción corresponde a ésta en exclusiva (artículo 31.3) y por otra, dado su carácter de órgano supremo, le permite tomar acuerdos obligatorios en materias, no consi- 
deradas por la Ley de su competencia exclusiva, que tampoco hayan sido encomendadas a otro órgano social (artículo 31). Ahora bien, debe tenerse en cuenta que como la normativa vasca atribuye un papel preponderante a los administradores y les asigna además de sus funciones propias, competencia residual sobre todas aquellas facultades que no estén atribuidas expresamente a otros órganos por la Ley o por los estatutos, será necesario que éstos prevean que esa atribución, en principio no encomendada por ley a ningún órgano social, corresponde a la asamblea. En caso contrario, en base a lo señalado en el último inciso del artículo 40, será competente el órgano de administración.

Los acuerdos cuya adopción corresponde en exclusiva a la asamblea general son los siguientes (artículo 31.3):

1. Nombramiento y revocación, por votación secreta, de los administradores, de los miembros de la comisión de vigilancia y de los liquidadores, así como, en su caso, de los miembros del comité de recursos y de los miembros del consejo social, y ejercicio de la acción de responsabilidad contra los mismos.

2. Nombramiento y revocación, que sólo cabrá cuando exista justa causa, de los auditores de cuentas.

3. Examen de la gestión social, aprobación de las cuentas anuales y de la distribución de excedentes o imputación de pérdidas.

4. Establecimiento de nuevas aportaciones obligatorias, del interés que devengarán las aportaciones a capital y de las cuotas de ingreso o periódicas.

5. Emisión de obligaciones, de títulos participativos o de participaciones especiales .

6. Modificación de los estatutos sociales ${ }^{8}$.

7. Constitución de cooperativas de segundo grado, corporaciones de cooperativas y entidades similares, así como la adhesión y separación de las mismas.

8. Fusión, escisión, transformación y disolución de la sociedad.

9. Toda decisión que suponga, según los estatutos, una modificación sustancial de la estructura económica, organizativa o funcional de la cooperativa.

8 Hay que tener en cuenta que en relación a esto se establece una excepción contenida en artículo 75, que se refiere al cambio de domicilio social dentro del mismo término municipal. 
10. Aprobación o modificación del reglamento interno de la cooperativa.

11. Todos los demás acuerdos en que así lo establezca la ley. El precepto se refiere a la ley en general, por lo que debe entenderse que se estaba pensando en cualquier ley que exija que determinada decisión sea competencia de la asamblea general, no únicamente en la Ley de Cooperativas. En distintos preceptos de la Ley vasca se recogen acuerdos que deben ser tomados por la asamblea general. ${ }^{9}$ Al margen de la Ley de Cooperativas, el caso más significativo es el de la cooperativa en quiebra que desea presentar una proposición de convenio con sus acreedores, ya que ésta deberá ser aprobada por aquélla (artículo 929, en relación con el artículo 934.3 del Código de Comercio).

En los supuestos anteriores y en los demás casos en que una norma legal exija que los acuerdos sean adoptados por la asamblea general, la competencia de ésta es indelegable. Sin embargo, a diferencia de la legislación anterior (artículo 31.3) en que la norma no admitía excepciones, para facilitar la creación de «superestructuras que puedan competir con otras ya establecidas», según señala la exposición de motivos, se establece que no es aplicable en relación a los procesos de integración cooperativa relativos a la constitución de cooperativas de segundo grado, corporaciones cooperativas y entidades similares y la adhesión a las mismas (artículo 31.5).

\section{Clases de asambleas generales}

Las asambleas generales pueden ser ordinarias y extraordinarias. Tradicionalmente, ha existido gran confusión en el ámbito societario a la hora de diferenciar unas y otras. Sobre todo, planteaba dudas si la asamblea general ordinaria podría tratar cuestiones distintas a las expresamente mencionadas en la ley. Por eso, para aclarar el tema, la Ley vasca señala que la asamblea general ordinaria tiene por objeto principal el examen de la gestión social, aprobar, si procede, las cuen-

9 Como ejemplo para ilustrarlo podemos citar el artículo 43, donde se recoge el acuerdo de asignación de remuneraciones a los administradores, o el artículo 48 en relación al acuerdo sobre transacción o renuncia al ejercicio de acciones de responsabilidad frente a los administradores, el artículo 95.2, que se refiere a la aprobación del balance final de liquidación o el proyecto de distribución del haber social... 
tas anuales y, en su caso, resolver sobre la distribución de los excedentes o la imputación de pérdidas. Podrá, asimismo, incluir en su orden del día cualquier otro asunto propio de la competencia de la asamblea. Todas las demás asambleas tienen el carácter de extraordinarias (artículo 32). Es decir, tienen esa consideración las que no incluyan los asuntos que son objeto privativo de las ordinarias.

\section{Convocatoria de la asamblea general}

Para estudiar este tema nos parece oportuno tratar separadamente las siguientes cuestiones: órgano facultado para convocar la asamblea, forma de convocarla, publicidad y contenido de la convocatoria.

\section{III.1. Organo facultado para convocar la asamblea}

La asamblea general debe ser convocada por los administradores (artículo 33.1). La ordinaria dentro de los seis primeros meses siguientes a la fecha de cierre del ejercicio social. Si transcurre ese plazo sin que la hayan convocado, cualquier socio puede solicitar, a través de un requerimiento notarial o por otro medio fehaciente, la convocatoria de la asamblea y si los administradores no la convocan en el plazo de quince días, a contar desde la recepción del requerimiento, el socio podrá solicitar la convocatoria al Juez de Primera Instancia del domicilio social. El Juez deberá atender la solicitud si efectivamente han transcurrido los plazos y ha existido requerimiento fehaciente, debiendo asignar, además, quién ha de presidir la asamblea. Esa asamblea general, aunque haya sido convocada fuera de plazo, no perderá su condición de ordinaria (artículo 33.2).

La extraordinaria se reunirá, en cualquier momento, por iniciativa propia de los administradores, a petición de la comisión de vigilancia o a petición de los socios que representan, al menos, el veinte por ciento del total de votos, efectuada por medio de un requerimiento fehaciente a los administradores que incluya un orden del día. Si la asamblea general no fuera convocada en el plazo de treinta días a contar desde la recepción de la solicitud, se podrá solicitar, al igual que en el caso anterior, la convocatoria judicial (artículo 33.3).

Además de por los administradores o por el juez, en la Ley vasca se introduce la posibilidad de que la asamblea general, tanto ordinaria como extraordinaria, sea convocada, en aquellas cooperativas donde 
exista, por la comisión de vigilancia cuando lo estime necesario en interés de la cooperativa y los administradores hubiesen desatendido la petición de los socios y de la propia comisión (articulo 53.1.c).

\section{III.2. Forma de convocar la asamblea}

La asamblea general se convocará siempre mediante anuncio expuesto públicamente de forma destacada en el domicilio social y en cada uno de los demás centros en los que la cooperativa desarrolle su actividad, en su caso (artículo 33.5, párrafo primero).

Cuando la cooperativa tenga más de quinientos socios, o cuando lo exijan los estatutos, aunque la sociedad no tenga ese número de socios, les será aplicable una regla específica - prevista en el artículo 33.5, párrafo segundo-: la convocatoria se anunciará también en los diarios de gran difusión en el territorio histórico del domicilio social.

Las normas anteriores son imperativas, y por tanto de obligado cumplimiento, aunque, además, los estatutos pueden indicar otras medidas de publicidad para facilitar el conocimiento de la convocatoria por todos los socios.

Sin perjuicio de lo anterior, también debe tenerse en cuenta que la Ley permite prescindir de la convocatoria en las llamadas asambleas generales universales. Se admite está práctica porque todos los socios se encuentran presentes o representados y deciden por unanimidad constituirse en asamblea. Para acreditar esa decisión unánime se exige que aprueben y firmen el orden del día y la lista de asistentes todos los socios, aunque, a partir de ese momento, no es necesaria la permanencia de todos ellos (artículo 33.8).

\section{III.3. Publicidad de la convocatoria}

Para que la convocatoria sea eficaz no es conveniente que se realice con demasiada anterioridad o en fecha demasiado próxima a su celebración. Por eso, se prevé que se haga pública con una antelación mínima de diez días y máxima de sesenta días a la fecha en que haya de celebrarse (artículo 36.6). Dentro del plazo mínimo no se deben incluir ni el día del anuncio, ni el día de la celebración. Igualmente, a efecto del plazo debe tenerse en cuenta que en los plazos que la Ley señala por días se computan los hábiles, excluyéndose los feriados (Disposición adicional primera). 


\section{III.4. Contenido de la convocatoria}

La convocatoria deberá indicar, al menos, la fecha, la hora y el lugar de la reunión, en primera y segunda convocatoria, entre las cuales deberá transcurrir como mínimo media hora, y expresará con claridad, precisión y suficiente detalle los asuntos que componen orden del día (artículo 33.7) para que sean conocidos por los socios con antelación a la celebración de la asamblea. El orden del día lo redactan los administradores según su criterio. Sin embargo para que los socios puedan introducir asuntos de su interés, la Ley, en el artículo 33.3, señala que los socios que representen más del diez por ciento del total de votos podrán solicitar, en escrito dirigido a los administradores y en los cinco días siguientes al anuncio de la convocatoria, la introducción de uno o más asuntos en el orden del día. Los administradores están obligados a incluirlos y a publicar el nuevo orden del día con, al menos, la publicidad exigida legalmente y con una antelación mínima de cuatro días a la fecha de celebración de la asamblea, que no podrá posponerse por este motivo.

\section{Funcionamiento de la asamblea general}

Bajo esta rúbrica la Ley se refiere al lugar de celebración, al quórum de constitución y al derecho de asistencia y recoge las normas generales de desarrollo de la asamblea.

\section{VI.1. Lugar de celebración de la asamblea general}

En principio, la asamblea general, salvo si tiene el carácter de universal, debe celebrarse en la localidad donde radique el domicilio social. Sólo para los casos en que exista causa que lo justifique, los estatutos podrán fijar con carácter general otros lugares de reunión, o los criterios a seguir por los administradores para la determinación del lugar de celebración de la asamblea (artículo 34.1).

\section{IV.2. Quórum de constitución de la asamblea general}

Con el fin de que los asuntos sean debatidos y acordados por un número mínimo de socios se señala que, en primera convocatoria, la asamblea general quedará válidamente constituida cuando estén presentes o representados la mayoría de votos (téngase en cuenta que 
no siempre es equivalente a mayoría de socios). En caso de que no se alcanzase ese quórum, debe intentarse la constitución de la asamblea en segunda convocatoria, requiriéndose para su válida constitución que estén presentes o representados al menos socios que ostenten el diez por ciento de los votos o cien votos (artículo 34.2). Esas exigencias constituyen unos mínimos inderogables, aunque los estatutos pueden fijar un quórum superior.

En principio, basta alcanzar el quórum de asistencia al inicio de la sesión, salvo que los estatutos contengan una previsión en contra y exijan el mantenimiento del quórum mínimo durante toda la reunión.

No obstante, la Ley 1/2000, de 29 de junio, de modificación de la Ley Vasca de Cooperativas, flexibiliza la constitución de la asamblea general en determinados tipos de cooperativas como las agrarias y de consumo, evitando, en último término, la paralización del órgano supremo de la cooperativa. En este sentido, admite que los estatutos prevean una tercera convocatoria para dichas cooperativas, cualquiera que sea el número de votos presentes o representados, que sólo podrá celebrarse tras no haber alcanzado los quórums previstos en las dos anteriores.

\section{IV.3. Derecho de asistencia}

Tendrán derecho de asistencia los socios que lo sean al menos desde la fecha en la que se acordó la convocatoria de la asamblea general (artículo 34.3).

Salvo que los estatutos exijan la asistencia personal del socio, se admite la asistencia a la asamblea por la representación (artículo 34.4), aunque, a diferencia de las sociedades capitalistas, no es posible delegar en cualquier persona, sino tan sólo en otro socio. Que no ostente más de dos representaciones. La autorización habrá de concederse por escrito y con carácter especial para cada asamblea (como ya exigía el artículo 106.2 de la Ley de Sociedades Anónimas). En el caso de asamblea universal también es posible actuar a través de representante siempre que el socio conozca los asuntos que se van a tratar en ella; por eso el escrito en que se acredite la representación es libremente revocable, atribuyéndose tal valor al acto concluyente del representado de asistir personalmente a la asamblea.

Para alcanzar una mayor representatividad en las asambleas y basándose en que ciertas cooperativas dan respuesta a necesidades del 
grupo familiar, por lo que si, efectivamente, los estatutos lo prevén, en las cooperativas de consumo, de viviendas, agrarias, y en cualesquiera otras dirigidas a la satisfacción de las necesidades familiares (por ejemplo, en las cooperativas de enseñanza), los socios podrán hacerse representar en la asamblea general por su cónyuge u otro familiar con plena capacidad de obrar y hasta el grado de parentesco que admitan los estatutos, que también determinarán si se exigirá poder especial para cada sesión asamblearia o si el escrito de representación tendrá validez durante el período que aquellos señalen (artículo 34.4).

\section{IV.4. Desarrollo de la asamblea general}

La asamblea general será presidida por la persona designada por los estatutos, en defecto de previsión estatutaria, por quien presida el órgano de administración, y, a falta del presidente del consejo rector, por estar el cargo vacante o por ausencia, se supone que por justa causa dado que tiene obligación legal de asistir, por el socio que elija la asamblea (artículo 33.6). El presidente estará asistido por un secretario, designado también por los estatutos o por los socios asistentes a la asamblea (artículo 33.7).

Sólo es necesaria la votación secreta en los supuestos previstos en la Ley (por ejemplo, en los casos de elección para cargos sociales) o en los estatutos y cuando lo soliciten socios que representen el diez por ciento de los socios representantes o representados en la asamblea (artículo 34.8).

Sin embargo, serán nulos los acuerdos sobre asuntos que no consten en el orden del día, salvo si la Ley autoriza expresamente su adopción ${ }^{10}$ (artículo 34.9).

A la asamblea general deben asistir, los administradores sean o no sean socios. Los estatutos podrán autorizar u ordenar la asistencia de directores, gerentes, técnicos y demás personas que tengan interés en la buena marcha de los asuntos sociales ${ }^{11}$. Igualmente, la asamblea general podrá autorizar la presencia de cualquier otra persona (artículo 33.10).

10 Por ejemplo con el acuerdo de ejercitar la acción social de responsabilidad frente a los administradores.

11 Podemos decir, como ejemplo, que tendrán interés en «la buena marcha de los asuntos sociales» los trabajadores no socios. 


\section{Derecho de voto}

La regla general en las cooperativas de primer grado es la tradicional de "un socio, un voto» (artículo 35.1). Sin embargo, el legislador admite la posibilidad de establecer el voto plural siempre que se cumplan las siguientes prescripciones:

- Que exista una previsión estatutaria específica para introducirlo.

- Que la previsión se circunscriba a cooperativas, sociedades controladas por estas y entidades públicas, ya que con la excepción se pretende, sin vulnerar el espíritu cooperativo, fomentar la participación de esas personas jurídicas para así potenciar la creación de nuevas entidades cooperativas y consolidar las ya existentes.

-Que los estatutos fijen con claridad los criterios de proporcionalidad del derecho del voto, teniendo en cuenta, por una parte, que el derecho de voto debe ser proporcional a la actividad cooperativa con la sociedad o a las prestaciones complementarias a está actividad en el marco de la intercooperación y, por otra parte, que el número de votos de un socio que no sea sociedad cooperativa no podrá ser superior al tercio de los votos totales (artículo 35.2).

Por el contrario, en las cooperativas de segundo grado la regla general es el voto plural: proporcional a la participación en la actividad cooperativa o a su número de socios (artículo 131). En las de crédito, la posibilidad de voto plural no viene impuesta por la Ley, si no que precisa previsión estatutaria (artículo 9.2 d la Ley 13/1989, de 26 de mayo de Cooperativas de Crédito, y artículo 35.3 de esta Ley).

Cuando en la cooperativa concurran socios colaboradores, inactivos o no usuarios o con vínculos de duración determinada, los estatutos deberán velar porque el porcentaje de votos de cada colectivo no supere el límite fijado para él con carácter especial12. Pero, además, como la Ley prohíbe que el total de votos de los socios colaboradores

12 Téngase en cuenta que el conjunto de los socios colaboradores, salvo que sean sociedades cooperativas, no puede ser titular de más de un tercio de los votos, ni en la asamblea general ni en el consejo rector (artículo 19.2), que el conjunto de los socios con vínculos de duración determinada no puede ser titular de más de la quinta parte de los votos sociales (artículo 26.2) y que el conjunto de los votos de los socios inactivos o no usuarios tampoco puede ser superior a la quinta parte del total de votos sociales (artículo 30.2). 
los inactivos o no usuarios y los de vínculo de duración determinada alcance la mitad de los socios de la cooperativa (artículo 35.4) para que el control mayoritario de la entidad resida en aquellos socios que realizan la actividad cooperativa de una manera plena, los estatutos si concurren las tres categorías de socios reseñadas, deberán fijar el porcentaje de cada colectivo dentro de ese límite global. Igualmente, los estatutos deberán establecer los supuestos en los que, por conflicto de intereses el socio deba abstenerse de votar (artículo 35.5).

\section{El régimen de mayorías}

Como regla general los acuerdos de la asamblea general se adoptaran por más de la mitad de los votos válidamente emitidos, sin computar, a estos efectos, los votos en blanco ni las abstenciones (artículo 36.1) ${ }^{13}$ para los "acuerdos extraordinarios» (transformación, fusión, escisión y disolución), llamados así por referirse a decisiones relevantes en la vida de la cooperativa, será necesaria mayoría de 2/3 de los votos presentes o representados (de su número total y no del número de votos emitidos), siempre que el número de votos presentes y representados sea inferior a al setenta y cinco por ciento del total de votos de la cooperativa (artículo 36.2). La Ley ha pretendido simplificar y facilitar su adopción, ya que, por un lado, reduce los casos en que la Ley de 1982 (articulo 35.2) exigía mayoría reforzada ${ }^{14}$ (aunque debe te-

13 Con esta redacción se aclaran las dudas que planteaba el artículo 35 de la Ley del 82:

1. El precepto establecía como norma general que los acuerdos de la asamblea se adoptarían por mayoría simple de los votos presentes o representados, válidamente emitidos. Ciertamente, se interpretó que por mayoría simple debía entenderse la constituida por mas de la mitad de los votos, sin embargo, en base a la redacción no quedaba claro si se refería a más de la mitad de los votos o a mayor número de votos a favor de postura determinada, aunque ésta no alcanzase la mitad de los votos sociales.

2. ${ }^{\circ}$ Además era discutible si debían computarse los votos en blanco. Igualmente como aspecto positivo debe destacarse la supresión de la posibilidad de otorgar voto de calidad al presidente, que se recogía en la ley anterior, que era criticada en un contexto societario en el que el principio de "un hombre, un voto», debe ser premisa insoslayable.

14 La Ley derogada la exigía para la adopción de los siguientes acuerdos:

1. Emisión de obligaciones.

2. Aprobar y modificar el reglamento interno.

3. Fusión, escisión y disolución de la cooperativa. 
nerse en cuenta que la lista anterior no es cerrada ni exhaustiva, dado que en otros preceptos también se exige esa mayoría, por ejemplo, para el acuerdo de reactivación de la cooperativa disuelta o su prórroga, artículo 81.1 y 5) y, por otro la mayoría reforzada no es precisa cuando concurra el quórum del setenta y cinco por ciento del total de votos de la cooperativa. En ese caso, será suficiente la mayoría simple.

Las mayorías y porcentajes fijados en la Ley no pueden ser rebajados en los estatutos, aunque es posible, tanto en los acuerdos ordinarios como extraordinarios, que se incremente la mayoría exigible siempre o para determinados supuestos y en el caso de los acuerdos extraordinarios también puede incrementarse el quórum de asistencia preciso para exigir o no mayoría reforzada. En la actualidad, no existe un tope máximo a la hora de incrementar las mayorías (a diferencia de la Ley de 1982 que lo fijaba en 3/4 partes de los votos presentes que cubran el quórum, artículo 35.3), aunque dado que en las sociedades rige el principio de decisión de la mayoría, no puede exigirse la unanimidad o un porcentaje tan elevado que prácticamente equivaliera a la unanimidad, y menos en las cooperativas dada su impronta democrática.

\section{Acta de la asamblea}

Los acuerdos de la asamblea general se consignarán en acta, que redactará el secretario y transcribirá en el libro de actas. En ella deberán recogerse, como mínimo, las circunstancias detalladas en el artículo 37.1, que sin perjuicio de que por previsión estatutaria o a iniciativa del secretario se incluyan, además, otras, son las siguientes:

-Fecha y lugar de la reunión.

-Fecha y modo en que se hubiera efectuado la convocatoria, salvo que se trate de asamblea universal.

- Texto íntegro de la convocatoria.

4. ${ }^{\circ}$ Creación de cooperativas de segundo y ulterior grado o de crédito y nombramiento de los interventores de cuentas.

5. Enajenación o cesión de la cooperativa por cualquier título, o de alguna parte de ella que tenga la consideración de centro de trabajo, o de algunos de sus bienes, derechos o actividades que supongan modificaciones sustanciales en la estructura económica o funcional de la cooperativa.

6. Acuerdo de modificación de estatutos. 
-El número de socios concurrentes, indicando cuántos lo hacen personalmente y cuantos asisten por representación, y si se celebra la asamblea en primera o segunda convocatoria.

- Un resumen de los asuntos debatidos y de las intervenciones de las que se haya solicitado constancia.

- El contenido de los acuerdos adoptados.

- El resultado de las votaciones, expresando las mayorías con que se hubiera adoptado cada unos de los acuerdos. Siempre que lo solicite quien haya votado en contra, se hará constar su oposición a los acuerdos.

— Los acuerdos del acta, cuando se hubiera producido al finalizar la reunión.

La lista de asistentes debe configurar al comienzo de la propia acta o adjuntarse a ella, por medio de anejo firmado por el secretario con el visto bueno del presidente. Para facilitar su confección en las sociedades con cierto número de socios podrán formarse mediante fichero o incorporarse a suporte informático, con los requisitos establecidos en el Registro Mercantil para las sociedades de esta naturaleza (artículo 37.2). El Reglamento del Registro Mercantil, en esos casos, exige que se consigne en el acta el medio utilizado y que se extienda en la cubierta precintada del fichero o soporte la oportuna diligencia de identificación firmada por el secretario, con el visto bueno del presidente de la asamblea (artículo 98.2).

Al igual que en las sociedades anónimas el acta deberá ser aprobada por la propia asamblea, a continuación de haberse celebrado ésta, o en su defecto y necesariamente, dentro del plazo de quince días hábiles, por el presidente y dos socios, designados por la asamblea quiénes la firmarán además del secretario (articulo 37.3), aunque la Ley Vasca de Cooperativas, con sentido didáctico, aclara que los acuerdos producirían los efectos a ellos inherentes desde el momento en que hayan sido adoptados (artículo 37.5). Esa prescripción debe ser complementada con la referencia a los acuerdos de inscripción obligatoria, que deben presentarse en el Registro de Cooperativas dentro de los treinta días siguientes de la aprobación del acta (artículo 37.6). En estos casos la inscripción es necesaria para que el acuerdo produzca efectos frente a terceros de buena fe.

En este apartado del acta de la asamblea, a nuestro juicio, se echa de menos una previsión legal de la posibilidad de acta notarial (análoga a lo señalado en el artículo 113 de la Ley de Sociedades Anónimas, 
dada su utilidad en caso de importantes desavenencias entre los socios. Ello no significa que no sea posible que un notario levante acta de la sesión ${ }^{15}$, aunque, a diferencia de lo que sucede en las sociedades anónimas, los administradores no están obligados a requerir la presencia de notario cuando lo soliciten cierto número de socios, sino únicamente cuando lo apruebe la asamblea. Igualmente, la falta de previsión legal no permite que el acta notarial tenga el valor de acta de la asamblea.

\section{La asamblea de delegados}

Con la regulación de esta figura se pretende favorecer la participación en aquellas cooperativas en que concurran circunstancias que dificulten la presencia simultanea de todos los socios en la asamblea general para debatir los asuntos y adoptar los correspondientes acuerdos. Se trata de convocar antes de la asamblea general, unas reuniones para grupos de socios con características similares, las llamadas juntas preparatorias: en ellas se estudian los asuntos del orden del día de la asamblea, aunque no se adoptan acuerdos sino que los socios individualmente delegan en algunos de ellos su voto para ser ejercido en la sesión asamblearia. Con ello la asamblea general se convierte en una asamblea de segundo grado, integrados únicamente por los delegados designados en las juntas preparatorias.

En la Ley Vasca la posibilidad de que la asamblea general se constituya como asamblea de delegados se supedita a la previsión estatutaria y a que la cooperativa tenga más de quinientos socios o concurran circunstancias que dificulten de forma grave y permanente la presencia de todos los socios en la asamblea general (artículo 38.1). A diferencia de a ley general que exige que únicamente concurran circunstancias que dificulten la presencia simultanea de todos los socios en la asamblea la Ley Vasca, utiliza un criterio más restrictivo al exigir la concurrencia de circunstancias graves y permanentes: no es suficiente, por tanto, una dificultad de poca importancia o transitoria.

15 Posibilidad admitida expresamente por los artículos 36.1.a y 51.1 de reglamento del Registro Cooperativo. 


\section{Impugnación de acuerdos de la asamblea general}

En esta materia, la Ley incorpora los criterios aplicables a la impugnación de acuerdos de sociedades de capital. Por eso (en términos similares al artículo 115 de la Ley de Sociedades Anónimas) señala que podrán ser impugnados los acuerdos de la asamblea general que sean contrarios a la Ley, se opongan a los estatutos o lesionen, en beneficio de uno o varios socios o de terceros, los intereses de la cooperativa (artículo 39.1); que serán nulos los acuerdos contrarios a la Ley y anulables los demás acuerdos mencionados (artículo 39.2) y que, aunque el acuerdo sea nulo o anulable, no procederá su impugnación, porque carecería de sentido, si se hubiese dejado sin efecto o hubiese sido sustituido válidamente por otro. Si fuera posible eliminar la causa de impugnación, el Juez otorgará un plazo razonable para que aquélla pueda ser subsanada (artículo 39.3): posibilidad que resulta muy útil para los acuerdos legítimos en cuanto al fondo y contenido, pero que se han adoptado prescindiendo de ciertos requisitos de forma, por ejemplo, sin observar los requisitos exigidos para la convocatoria de la asamblea. En un caso como éste el Juez otorgaría un plazo para repetir la asamblea, esta vez correctamente convocada, y reiterar el acuerdo.

Igualmente siguiendo la normativa de la sociedades de capital (artículo 116 y 117 de la Ley de Sociedades Anónimas), se establece un régimen distinto para la acción de impugnación de acuerdos nulos y para la acción de impugnación de los acuerdos anulables. La acción de impugnación de los acuerdos nulos podrá ser ejercitada por todos los socios, los administradores, los miembros de la comisión de vigilancia y cualquier tercero con interés legítimo, y caducará en el plazo de un año, con excepción de los acuerdos que resulten contrarios al orden público (artículo 39.4). Para ejercitar la acción de impugnación de los acuerdos anulables están legitimados los socios asistentes que hubiesen hecho constar en el acta de la asamblea general su oposición al acuerdo, los ausentes y los que hubiesen sido ilegítimamente privados de voto, así como los administradores o los miembros de la comisión de vigilancia, y caducará a los cuarenta días (artículo 39.5). Los plazos caducidad se computarán desde la fecha de adopción del acuerdo, o , si fuera inscribible; desde la fecha de su inscripción en el Registro de cooperativas (artículo 39.6).

Ambas acciones se acomodarán, para su ejercicio, al procedimiento específico contemplado en los artículos 118 a 121 de la Ley de régi- 
men jurídico de las sociedades anónimas, con la salvedad de que para solicitar en el escrito de demanda la suspensión del acuerdo impugnado se exigirá que el demandante sea la comisión de vigilancia o socios que representen, al menos, un veinte por ciento del número de votos (artículo 39.7) ${ }^{16}$.

En principio, las sentencias producen efectos frente a todos. Sin embargo, para salvaguardar los derechos de los terceros de buena fe que pudieran verse afectados por la decisión judicial, la Ley, en consonancia con las sentencias actuales de Derecho societario (artículo 122 de la Ley de Sociedades Anónimas), señala que la sentencia estimatoria de la acción de impugnación producirá efectos frente a todos los socios pero no afectará a los derechos adquiridos por los terceros de buena fe a consecuencia del acuerdo impugnado. En el caso de que el acuerdo impugnado estuviese inscrito en Registro de Cooperativas, la sentencia determinará su cancelación (artículo 39.8).

\section{LOS ADMINISTRADORES}

\section{Concepto}

Lo cierto es que la Ley de Cooperativas del País Vasco no ofrece una definición de administrador; sino que más bien alude a las competencias que le son propias en exclusiva. El artículo 40, que abre la sección 2. ${ }^{a}$ de la administración y representación de la cooperativa correspondiente al capítulo $\mathrm{V}$ los órganos de la cooperativa, indica que los administradores son el órgano al que corresponde en exclusiva la gestión y la representación de la cooperativa, y añade que ejercen además todas las facultades que no estén expresamente reservadas por la ley o los estatutos a otros órganos sociales. Si bien nuestra labor ha de estar centrada en las novedades aportadas por la Ley 1/2000 resulta inevitable destacar las virtudes que la Ley 4/1993 adquirió en relación con su antecedente de 1982. Tal es el caso de la expresa atribución en exclusiva de sus competencias, lo que en anterior legislación no resultaba tan claro, así como la competencia residual sobre facultades no atribuídas a otros órganos.

16 En el caso de las sociedades anónimas se exige la solicitud de un número de socios que detenten un cinco por ciento del capital social (artículo 120). 
En lo concerniente a la representación de la cooperativa debemos señalar tres aspectos fundamentales. Por una parte la representación se extiende en juicio o fuera de él a todos los actos comprendidos en el objeto social. Debe entenderse, y así lo hace GaDEA ${ }^{17}$ que el ambito de representación se extiende tanto a los actos comprendidos en el objeto social como en los actos conexos, esto es aquellos que constituyen un medio auxiliar para el desarrollo de aquel. Por otra parte no resultará eficaz frente a terceros limitación estatutaria alguna de las facultades representativas. Finalmente y en un auténtico ejercicio de protección de terceros pero también de aceptación de la realidad de la vida societaria la Ley indica que la cooerativa quedará obligada frente a terceros que hayan obrado de buena fe y sin culpa grave, aunque el acto no estuviera comprendido en el objeto social.

Finalmente no podemos dejar de señalar que, si bien sólo los administradores pueden tener la representación de la sociedad, ésta no tiene porqué ser atribuida a todos.

\section{Naturaleza de los miembros}

En primer lugar debemos señalar que la administración de la cooperativa se puede llevar a cabo por un órgano colegiado, que decide el nombre de consejo rector, o bien por un órgano unipersonal. Mientras que en el segundo caso el administrador debe ser además socio de la cooperativa en el primero cabe la posibilidad de que una cuarta parte de los miembros puedan no ser socios, salvo que lo prohiba el estatuto. Así lo establece el artículo 41.2.

Hemos señalado así una segunda idea como es la de que la administración esté tanto en manos de socios como en las de profesionales.

En tercer lugar y relacionándolo con los socios debemos aludir a una posibilidad que desarrollaremos más adelante; no es otra que la posibilidad de que cada colectivo de socios a los que se refiere el artículo 45.4 tiene derecho a elegir en la asamblea el número de consejeros que le corresponda sin intrevenir en la elección del resto.

En cuarto lugar hay que indicar que puede nombrarse administrador tanto a una persona física como a una jurídica, caso este último

17 Gadea E., D. ${ }^{\circ}$ de las Cooperativas (Análisis de la Ley 4/1993 de 24 de junio, de Cooperativas del País Vasco). Deusto 2. ${ }^{a}$ ed.; p. 181. 
que exigiría la designación de una persona física para el ejercicio de las funciones propias del cargo (artículo 41.4).

Finalmente no podemos obviar que si bien no hay condiciones especiales para ser administrador en el artículo 42 se especifican un serie de supuestos de incapacidad y prohiciones que impiden el acceso al cargo. Estos son los casos:

a) Los quebrados y concursados no rehabilitados, los menores e incapacitados, los condenados a penas que lleven aneja la inhabilitación para el ejercicio de cargos públicos, los que hubieran sido condenados por grave incumplimiento de leyes o disposiciones sociales y aquellos que por razón de su cargo no puedan ejercer actividades económicas lucrativas.

b) Los funcionarios y personal al servicio de la administración, con funciones a su cargo que se relacionen con las actividades propias de la cooperativa de que se trate.

c) Los que desempeñen o ejerzan por cuenta propia o ajena actividades competitivas a las de la cooperativa, o que bajo cualquier forma tengan intereses opuestos a los de la misma.

d) Los miembros de la comisión de vigilancia y del comité de recursos, y los directores-gerentes.

e) Los incursos en los supuestos estatutariamente previstos.

El apartado 2 del artículo 42 es claro cuando especifica que la incurrencia en cualquiera de estos supuestos exige la dimisión inmendiata. Añade que en caso de no producirse la dimisión el administrador podrá ser suspendido _por la Comisión de vigilancia o en su defecto por el propio Consejo rector- hasta la celebración de la siguiente Asamblea general. Agrega el citado precepto que siempre que se haya producido la suspensión cautelar o a petición de cualquier socio la Asamblea general destituirá al administrador afectado salvo en el caso c) en el que la Asamblea decidirá libremente su cese o continuidad.

Hay en este apartado dos cuestiones con riesgo de ser malinterpretadas. Así lo expresa GADEA ${ }^{18}$ cuando en primer lugar advierte de la inaplicabilidad de la suspensión para el caso del administtrador único, y en segundo lugar señala que la destitución llevada a cabo por la

18 GAdeA E., D. ${ }^{\circ}$ de las Cooperativas (Análisis de la Ley 4/1993 de 24 de Junio, de Cooperativas del País Vasco). Deusto 2. ${ }^{a}$ ed.; p. 183. 
Asamblea no sólo depende de la sustitución previa o de la solicitud por un socio sino de la apreciación por la propia Asamblea de la incurrencia del Administrador en alguno de los supuestos del artículo 42.1. Por último hay que tener en cuenta que el acuerdo de la Asamblea a este respecto es impugnable ante la jurisdicción ordinaria.

\section{Nombramiento de los administradores, duración del cargo y cese}

Para explicar la regulación concerniente a la elección de los administradores debemos remontarnos al artículo 41, en cuyo apartado 3 se especifica que éstos deben ser elegidos por la Asamblea general por mayoría relativa; es decir, por el mayor número de votos válidos emitidos en votación secreta, con la excepción ya aludida anteriormente del supuesto del artículo 45.4, en cuyo caso cada colectivo de socios afectado podrá elegir directamente en la asamblea el número de consejeros que le corresponda sin intervenir en la elección del resto.

En lo concerniente a la eficacia del nombramiento debemos distinguir si estamos refiriéndonos a las relaciones del administrador con la sociedad, en cuyo caso el nombramiento surte efectos desde la aceptación, o si estamos refiriéndonos a las relaciones con terceros pues en ese caso es necesario dar publicidad al nombramiento a través de la inscripción registral.

Por otra parte, y de acuerdo con lo indicado por el último apartado del artículo 41 el Consejo rector puede conferir tanto apoderamientos generales a uno o varios directores generales, como apoderamientos singulares a cualquier persona.

En lo referente a la duración del cargo el artículo 44 indica que el plazo será fijado en los Estatutos entre dos y cinco años. Cabe, no obstante la reelección indefinida por períodos de igual magnitud, pudiendo continuarse provisionalmente en el cargo transcurrido el plazo hasta la celebración de Asamblea general.

Finalmente es también la Asamblea general la que esta facultada para decidir sobre la destitución de los administradores, incluso aún no constando en el orden del día, si bien en este caso se necesitarán las dos terceras partes de los votos presentes y representados en la 
Asamblea para su aprobación. Además toda destitución debe llevar aparejada la elección de los nuevos administradores. Al igual que ocurría con el nombramiento la destitución sólo tendrá efectos frente a terceros previa inscripción registral, no siendo ésta necesaria para la relación entre cooperativa y administrador cesado.

\section{Composición y renovación del consejo rector}

Con este encabezamiento se da nombre al artículo 45 que especifica que los estatutos establecen la composición del Consejo rector. En cualquier caso el número de sus miembros no podrá ser inferior a tres. Para los casos de vacantes definitivas los estatutos pueden prever igualmente la existencia de administradores suplentes y he aquí una excepción al mecanismo de elección de los administradores, explicado en líneas anteriores, ya que son los propios estatutos los que indican el sistema de elección y sustitución y es que la Ley no exige que los suplentes sean elegidos por la Asamblea.

Por otra parte, y respecto a una posibilidad a la que ya que ya nos hemos referido anteriormente tenemos que señalar que los estatutos pueden prever que la composición del Consejo rector refleje entre otras circunstancias, su distinta implantación geográfica, las diversas actividades desarrolladas por al cooperativa, las diferentes clases de socios y la proporción existente entre ellos, estableciendo las correspondientes reservas de puestos. Como bien señala GADEA esta enumeración no es un numerus clausus sino que debemos ententer que la reserva de puestos está abierta a otras posibilidades ${ }^{19}$.

Finalmente cabe señalar que el Consejo rector elegirá entre sus miembros los cargos de presidente y secretario. Además se renovará parcialmente y los consejeros podrán ser reelegidos indefinidamente, si bien este extremo ya había sido descrito en el apartrado anterior.

\section{Remuneración}

Aunque el cargo de administrador no es necesariamente remunerado los estatutos o la Asamblea general así lo pueden establecer.

19 GAdeA E., D. de las Cooperativas (Análisis de la Ley 4/1993 de 24 de Junio, de Cooperativas del País Vasco). Deusto 2. ${ }^{a}$ ed.; p. 186. 
GADEA se refiere a este extremo señalando que es sorprendente la ausencia de todo límite legal a esta remuneración en comparación con la Ley general e incluso con la Ley de Sociedades Anónimas ${ }^{20}$.

\section{Funcionamiento del Consejo rector}

Si bien el funcionamiento interno del Consejo rector se regula en los estatutos el propio órgano de administración puede regular su funcionamiento en lo que no prevean aquellos. En cualquier caso deben respetarse las prescripciones legales. Tales son:

- Convocatoria: Corresponde al presidente del Consejo.

-Quórum: El Consejo quedará válidamente constituido cuando concurran a la reunión más de la mitad de sus componentes; no obstante, este quórum puede ser incrementado estatutariamente. En cualquier caso la asistencia de los administradores debe ser personal, no se permite ningún tipo de representación.

- Acuerdos: Cada consejero tendrá un voto. La adopción de acuerdos exige al menos la mitad de los votos de los consejeros asistentes, excepción hecha por Ley o estatutos. No obstante hay una serie de acuerdos que, debido a su relevancia societaria o económica, exigen el voto favorable de dos tercios de los asistentes:

- Cierre o traslado de un centro principal de actividad o de una parte significativa del mismo.

— Restricción, ampliación o modificación substanciales de la actividad cooperativa.

- Cambios de trascendencia para la organización de la cooperativa.

- Establecimiento o extinción de vínculos con otras entidades, cooperativas o no, que supongan una relación de colaboración permanente y valiosa para la cooperativa.

- Actas: Los debates, acuerdos y resultados de las votaciones de cada reunión así como la lista de asistentes, la fecha, el lugar de reunión y en general las previones señaladas para el acta de la Asamblea general serán recogidos en un acta firmada por el presidente y el secretario, que a su vez se llevará a un libro de actas.

20 GadeA E., D. ${ }^{\circ}$ de las Cooperativas (Análisis de la Ley 4/1993 de 24 de Junio, de Cooperativas del País Vasco). Deusto 2. ${ }^{a}$ ed.; p. 184. 
Comisión ejecutiva y consejeros delegados: En primer lugar debe señalarse que tanto para la designación de los miembros de la comisión como para la de los consejeros delegados es necesaria una mayoría de las dos terceras partes de los componentes del Consejo rector. En lo que se refiere a la delegación cabe indicar que la delegación permanente de alguna facultad del Consejo ya sea en la comisión ya sea en el consejero delegado exige esta misma mayoría. Además son indelegables la rendición de cuentas, la presentación de balances a las Asamblea general, y las facultades que ésta conceda al consejo rector salvo expresa autorización por aquélla.

\section{Responsabilidad}

Con respecto a la responsabilidad de los administradores debemos remitirnos al artículo 47 para concretar las características de dicha responsabilidad y al artículo 48 para las acciones de exigencia de dicha responsabilidad.

Respecto al primer apartado podemos distinguir cinco aspectos diferenciados:

El criterio de graduación de la responsabilidad es la actuación diligente, concretamente se exige que los administradores desempeñen su cargo con la diligencia de un ordenado empresario y un representante leal, respondiendo de los daños que causen por actos contrarios a la ley, a los estatutos o realizados sin la diligencia debida, que deberá estimarse con más o menos rigor en función del carácter retribuido o no del cargo. Se exige además que guarden secreto sobre los datos que tengan carácter confidencial incluso tras haber cesado en sus funciones - GADEA entiende que son aquellos cuya difusión pueda perjudicar los intereses sociales ${ }^{21}$-.

El régimen de responsabilidad incluye a criterio de GADEA serie de requisitos ${ }^{22}$ como son:

- De la conducta del administrador ha de derivarse un daño para la sociedad y se responderá en función de su cuantía.

21 Gadea E., D. ${ }^{\circ}$ de las Cooperativas (Análisis de la Ley 4/1993 de 24 de Junio, de Cooperativas del País VasCo). Deusto 2. ${ }^{a}$ ed.; p. 188.

22 Gadea E., D. ${ }^{\circ}$ de las Cooperativas (Análisis de la Ley 4/1993 de 24 de Junio, de Cooperativas del País Vasco). Deusto 2. ${ }^{a}$ ed.; p. 189. 
- Si bien para algunos autores la responsabilidad se determina de manera objetiva por la actuación en contra de la ley o los estatutos, siendo la culpa un criterio únicamente relevante para los actos realizados sin la diligencia debida, para otros la culpa es un presupuesto general de responsabilidad con lo que si la responsabilidad del administrador se deriva de la infracción del deber genérico de actuación diligente el demandante tendrá que probar la culpa, mientras que si proviene de la infracción de la ley o los estatutos tendrá que ser el administrador el que demuestre que actuó con la diligencia debida.

- Debe haber un nexo de causalidad entre la conducta y el perjuicio.

- El régimen de responsabilidad de los administradores es de orden público de manera que cualquier acuerdo modificatorio es nulo de pleno derecho.

Siguiendo la propia estructura del precepto legal descubrimos que el carácter de la responsabilidad de los administradores es solidario lo que implica que:

- Cada administrador responderá de la totalidad de la deuda indemnizatoria.

- Los que ejerciten la acción social de responsabilidad podrán dirigirse contra cualquiera de los administradores, contra todos o contra varios indistintamente e incluso simultáneamente.

- El administrador que haya pagado la deuda tendrá una acción de regreso contra el resto de administradores deudores por la cantidad correspondiente.

Hay una serie de supuestos cuya concurrencia exonera de responsabilidad:

—Desconocimiento por el administrador de la existencia del acuerdo.

- En caso de tener conocimiento de la reunión en la que se vaya a tomar el acuerdo lesivo el administrador debe hacer todo lo posible por evitarlo.

- El administrador debe al menos haberse opuesto expresamente al acuerdo lesivo; es decir, además de haber votado en contra debe haber hecho constar su oposición en el acta.

En quinto y último lugar debemos aludir al mecanismo de protección de acreedores y minorías en la cooperativa frente al posible 
intento de una mayoría de socios que traten de exonerar de responsabilidad a los administadores mediante la adopción, autorización o ratificación del acto lesivo por la Asamblea general. Pues bien, ninguna de estas técnicas supondrá tal exoneración.

El segundo aspecto que tenemos que estudiar al analizar la responsabilidad de los administradores es el referido a las acciones contra ellos. El artículo 48 distingue la acción social de responsabilidad de las acciones individuales de responsabilidad.

La acción social de responsabilidad tiene como finalidad el resarcimiento de los daños sufridos por la sociedad por lo que la indemnización correspondiente se destinará al patrimonio de la sociedad. Debemos tener en cuenta que sea cual sea el caso la acción prescribirá a los dos años de producirse los actos que generen la responsabilidad cuando estos se conozcan o a los dos años de que sean conocidos. La legitimación activa de esta acción es diversa:

- De una parte la cooperativa puede ejercitar la acción a través de un acuerdo de la Asamblea general por mayoría ordinaria. Debemos añadir que con independencia de que el acuerdo suponga la promoción de la acción o la transigencia, se producirá la destitución de los administradores afectados.

- Pasados tres meses desde la adopción del acuerdo lesivo por el Consejo rector sin que la cooperativa haya entablado la acción de responsabilidad cualquier socio podrá ejercitarla.

- Finalmente seis meses tras producirse el daño y sin interposición de la acción cualquier acreedor social podrá hacerlo. En la práctica es más frecuente que éste opte por la acción individual.

Precisamente podemos ahora aludir a las acciones individuales de responsabilidad. En este caso el objetivo es el resarcimiento de los daños sufridos directamente por un socio o un tercero. El artículo 48 se remite a la regla general del Derecho privado de que se deben reparar los daños causados a otro por acción u omisión dolosa o culpable. No obstante, dependiendo de si nos encontramos ante una acción de responsabilidad extracontractual o una de responsabilidad contractual, deberemos aplicar un régimen legal u otro; de manera que la doctrina ha distinguido entre la acción individual ejercitada por terceros o socios en calidad de terceros, frente a actos ilícitos de los administradores como acción del primer caso, y la acción de indemnización contra 
los administradores por el incumplimiento culposo de sus funciones por parte del socio como titular de una acción contractual23.

\section{Impugnación de acuerdos}

El artículo 49 abre la posibilidad de que los acuerdos del Consejo rector o de la comisión ejecutiva sean impugnados cuando vulneren la ley, en cuyo caso serán nulos de pleno derecho, o cuando vulneren los estatutos o lesionen los intereses de la cooperativa en beneficio de algún socio o de terceros, en cuyo caso serán anulables.

Los sujetos legitimados serán:

- Los administradores y la comisión de vigilancia en el plazo de sesenta días desde la adopción del acuerdo.

- Los socios a título individual cuando se trate de actos nulos y el diez por ciento de los votos sociales si se trata de actos anulables. Igualmente se someten a un plazo de sesenta días desde que tuvieron conocimiento y siempre que no haya transcurrido un año desde su adopción.

El citado precepto se remite a la regulación de la impugnación de los acuerdos de la Asamblea general en lo referente a los efectos y tramitación.

\section{LA COMISION DE VIGILANCIA}

\section{Composición, mandato y nombramiento}

Hemos escogido este encabezamiento porque es precisamente el que titula el artículo 50 que inaugura la sección tercera referida a la Comisión de Vigilancia. Sin embargo, a tenor de su contenido podríamos ofrecer unos apartados con denominación distinta.

En lo que se refiere a la naturaleza de este órgano podríamos decir que se ocupa de fiscalizar y controlar y que está pensado para sociedades de un considerable tamaño. Es más el propio artículo 50

23 GAdeA E., D. de las Cooperativas (Análisis de la Ley 4/1993 de 24 de Junio, de Cooperativas del País Vasco) Deusto 2. ${ }^{a}$ ed.; pp. 193 y 194. 
señala que esta comisión no será obligatoria cuando el número de socios de la comisión resulte inferior a cien.

En lo concerniente a los miembros podemos comenzar señalando que su número que será fijado por los estatutos no puede ser inferior a tres; por otra parte el período de duración del mandato no podrá coincidir con el de los administradores e igualmente quedará fijado por los estatutos. Tanto los socios como aquellos terceros que reúnan los requisitos de honorabilidad, cualificación profesional y experiencia técnica o empresarial adecuados en relación con las funciones de la comisión podrán ser miembros de la misma.

Respecto a la elección o nombramiento cabe indicar que los miembros serán elegidos y revocados siempre mediante votación secreta, por el mayor número de votos válidamente emitidos en la Asamblea general. Se trata además de cargos reelegibles salvo disposición estatutaria en contra.

\section{Facultades de información}

De acuerdo con el artículo 51 los administradores deben informar a la comisión de vigilancia, al menos una vez por trimestre, de las actividades y evolución previsible de la cooperativa. A su vez la propia comisión podrá realizar todas las comprobaciones que estime oportuno para el desempeño de su función ya sea a través de sus miembros o a través de expertos.

\section{Ambito de actuación}

Con el objetivo de preservar el buen funcionamiento de la administración de la sociedad cooperativa el artículo 52 señala que la comisión de vigilancia no podrá intervenir directamente en la gestión de la cooperativa, ni representar a ésta ante terceros pero sí ante el propio órgano de administración.

\section{Competencias y funcionamiento}

Mientras que el legislador ha resultado increíblemente exhaustivo y celoso en lo referente a las competencias de la comisión de vigilan- 
cia al detallar en el artículo 53 un extenso listado; da una amplia libertad reguladora del funcionamiento de ésta ya sea mediante estatuto o mediante reglamento interno, pues únicamente exige que cualquier administrador o miembro de la propia comisión pueda solicitar por escrito al presidente de este órgano la convocatoria del mismo, indicando los motivos de la petición. Añade además que cuando esta solicitud proceda de un tercio al menos de los miembros del Consejo rector o de la propia comisión y ésta no fuese convocada en el plazo de un mes, cualquiera de los grupos solicitantes podrá efectuar la convocatoria. Por último y para evitar un defecto funcional se permite el funcionamiento de la comisión durante el período de liquidación, si bien deberá limitarse a aquellas funciones que resulten procedentes en dicho período.

\section{EL CONSEJO SOCIAL}

Su existencia es facultativa y puede ser prevista estatutariamente en aquellas cooperativas que cuenten con más de cincuenta trabajadores o socios de trabajo. Y es que el órgano que regula el artículo 54 tiene un carácter de representación de estos socios y sus funciones son las de informar, asesorar y consultar a los administradores en todo aquello que pueda afectar a la relación de trabajo. Se exige además la emisión de un informe preceptivo aunque no vinculante, al respecto.

\section{EL COMITE DE RECURSOS}

Se trata también de un órgano potestativo si bien está abierto a todo tipo de cooperativas. En cualquier caso si vía estatutaria se establece su creación, esta se someterá a una serie de requisitos legales enumerados en el artículo 55.

\section{CONSEJO SUPERIOR DE COOPERATIVAS DEL PAIS VASCO}

\section{Introducción}

El asociacionismo cooperativo es un elemento constitutivo de la esencia del fenómeno cooperativo. Tiene dos vertientes: 
- La conjunción con fines económico-empresariales

- Y la de carácter representativo del movimiento cooperativo.

Es en esta vertiente representativa donde encuadramos al Consejo Superior de cooperativas

\section{Esbozo Histórico}

El Consejo Superior de cooperativas es una de las instituciones más importantes en el entorno cooperativo vasco 24 .

La figura del Consejo Superior tiene su origen en Francia en $1918^{25}$.

Posteriormente la Ley de Cooperativas de 1934 de la Generalidad de Cataluña lo integró en la legislación cooperativa española ${ }^{26}$, aunque su existencia dada la Guerra Civil fue de pocos años.

En la Ley de cooperación de 2 de enero de 1942 (artículo 57) y en su Reglamento de 1943 (artículo 80), aparece bajo el marco de la Organización Sindical como el más alto organismo de la Obra Sindical de Cooperación.

Será ya dentro del marco constitucional, cuando el legislador de la Ley 1/1982 inspirado por el Consejo de Cataluña de 1934, lo instaura dentro de su marco legal cooperativo como el máximo órgano de promoción y representación de las cooperativas y sus organizaciones ${ }^{27}$.

En este período histórico el Consejo Superior es dotado de personalidad jurídica y plena capacidad de obrar.

Igualmente se le asigna como principio informador supremo el fomento y estudio cooperativista (artículo 70.1 Ley 1/1982)

Del mismo modo va a cumplir los siguientes cometidos:

— difundir los principios del movimiento cooperativo

—informar proyectos y disposiciones legales y reglamentarias en materias de cooperativas;

24 Un detallado análisis del tema puede verse en Buitrón AndRADE, P., Análisis estructural y delimitación de las funciones del Consejo Superior de Cooperativas de Euskadi. 1. ${ }^{a}$ edición. Consejo Superior de Cooperativas de Euskadi, 1998.

25 Decreto de 22 de febrero de 1918.

26 Ley de Bases de la Cooperación para Cooperativas, Mutualidades y Sindicatos Agrícolas de 17 de febrero de 1934. Artículo 22.

27 Buitrón Andrade, P., El Consejo Superior de Cooperativas de Euskadi. 
— proteger y defender los intereses legítimos de la cooperación;

- contribuir al perfeccionamiento del régimen legal;

- el arbitraje cooperativo;

-y, cuanto sea beneficioso para la cooperación y sus entidades (artículo 70.2 Ley 1/1982).

Las restantes Leyes de cooperativas de las Comunidades Autónomas que se expidieron a continuación de la Ley $1 / 1982^{28}$, e incluso la derogada Ley 3/1987, General de Cooperativas ${ }^{29}$, contemplaron también esta figura con similares funciones, aunque fijando su dependencia a las instancias administrativas.

\section{III. ¿Qué supuso la instauración del Consejo Superior de cooperativas?}

Podemos destacar que la aparición del Consejo Superior de cooperativas marca tres etapas en la estructura institucional del Cooperativismo vasco:

-la primera comprende desde sus inicios hasta la creación de este Consejo;

- la segunda, el período de su labor como representante atípico de las cooperativas y de sus organizaciones;

-y, la tercera, a partir de la creación y constitución de la Confederación de cooperativas.

\section{Notas a destacar}

La importancia fundamental de esta figura jurídico-cooperativa, como hemos tenido oportunidad de señalar en un inicio, radica en que en su seno se gestó el proceso de creación de las federaciones de cooperativas, cuyo punto máximo se encuentra en la Confederación ${ }^{30}$.

28 Leyes de Cooperativas de las Comunidades Autónomas de Cataluña, Andalucía, Valencia, Navarra.

${ }_{29}$ Consejo Superior del Cooperativismo derogado por efecto del artículo 98.5 de la Ley 31/1990, de 28 de diciembre, de Presupuestos generales del Estado para 1991.

30 Organo importante en el asociacionismo cooperativo también incardinado en la vertiente de carácter representativo del movimiento cooperativo. 
Hasta ese momento el Consejo Superior había asumido una extraña representación que se plasmaba en la presencia, voz e interlocución del Cooperativismo vasco en distintos foros tanto nacionales como internacionales.

La prueba de tan atípica representación fue su participación en la Alianza Cooperativa Internacional.

El Consejo Superior asumió por mandato de la Ley el espacio que tenía que ser cubierto por un ente enteramente cooperativo pero que no existía ni se creaba. Tampoco encontró oposición desde las esferas cooperativas.

De hecho es mencionable la participación activa de los representantes cooperativos en él.

De este modo asumió el papel de foro de consenso, encuentro y diálogo con la Administración.

\section{Naturaleza}

La naturaleza jurídica del Consejo es una de sus notas características por su peculiaridad. Se trata de un híbrido de varias líneas de regulación jurídica; funciona como una válvula legal que responde a la funcionalidad de objetivos determinados que se persigue lograr sin atender a un patrón legal definido en el marco jurídico.

En la Ley 4/1993 deja de ser el máximo representante de las cooperativas y de sus organizaciones, función asumida con pleno derecho por la Confederación, lo cual favorece a centrar de mejor manera su contenido. No obstante, ello no facilita completamente su delimitación legal.

La calificación de órgano no se ajusta a la de tal en la estructura jurídica-administrativa, por lo que técnicamente no es el término más adecuado.

Su naturaleza según la Ley 4/1993, es la de ser una entidad pública que cumple en principio un doble cometido: la de ser el máximo ente de promoción y difusión del Cooperativismo, y la de ser el ente consultivo y asesor de las administraciones públicas vascas en materias que afectan a éste, para lo cual goza de personalidad jurídica propia y plena capacidad de obrar (artículo 145.l). 
Tal y como se presenta la disposición legal el Consejo es un ente público por ser la Ley de Cooperativas la que lo crea, y por tanto se somete al Derecho público. No es un órgano porque tiene personalidad jurídica propia y no forma parte de la Administración. Sin embargo, al ser un ente público y al estar sometido al Derecho público en lo que tiene que ver con el régimen jurídico de adopción y el régimen jurídico de impugnación está regulado por el Derecho administrativo y por el contencioso-administrativo ${ }^{31}$. En todo caso, su condición de ente público hace que resulte extraña su inclusión en el Título IV de la Ley, «Del Asociacionismo Cooperativo».

La experiencia de la Ley 1/1982 motivó que el legislador buscara ajustar de mejor manera y con más precisión sus funciones, una vez constituida la estructura federativa y representativa del Cooperativismo vasco. Por lo mismo en la Ley 4/1993 se perfilan tres líneas básicas del contenido y por tanto de los fines que persigue; así, atendiendo a su composición se mantiene como ente de consenso, encuentro y diálogo de los distintos sectores que tienen en común la materia cooperativa; se mantiene también su condición de máximo órgano en la labor impulsora y promotora del Cooperativismo superponiéndose a las federaciones y a la Confederación; y mantiene además su capacidad de intervenir por vía arbitral en los asuntos a que está facultado. Por esto, y con carácter general, en la Ley de 1993 el Consejo es el ente público consultivo y asesor de las administraciones públicas vascas cuya misión es promover y difundir el Cooperativismo, siendo entonces su naturaleza más propia el ser el ente colaborador de la Administración especializado en materia cooperativa (artículo 145.1), con un régimen legal especial pues no se ajusta en propiedad a los que integran la estructura administrativa.

\section{Composición}

Ya en sus orígenes el Consejo ha estado compuesto por representantes de tres sectores: del sector cooperativo (mayoritariamente), de la Administración ${ }^{32}$ y de las Universidades ${ }^{33}$.

31 Buitrón Andrade, P., El Consejo Superior de Cooperativas de Euskadi

32 Lo integraban el Vice-Consejero de Relaciones Colectivas del Departamento de Trabajo y tres consejeros designados por el Gobierno Vasco.

33 Decreto 208/1982, de 15 de noviembre. La primera composición de este Consejo no democrática puesto que se eligió a quienes tenían más influencia en el ámbito cooperativo. 
Esta configuración se ha mantenido en la Ley 4/1993 (artículo 145.3). La representación de las cooperativas se realiza a través de las federaciones en las que aquéllas se integren, primando en la representación las que cumplan los requisitos del artículo 144.2.

Nuestra Universidad ha participado activamente en esta materia. Así como las Universidades del País Vasco (UPV). El fin era encontrar un modo de acercar al entorno académico este foro de decisión cooperativa.

El Consejo está presidido por el Director de Economía Social del Gobierno Vasco y cuenta con una Secretaría Técnica (artículo 145.4).

No obstante, con el nuevo Reglamento del Consejo Superior Cooperativas, de 2 de marzo de 2000, se introducen novedades en relación a su composición. Ahora está formado por un representante por cada federación de cooperativas, tres miembros serán designados por el Gobierno Vasco, siendo uno de ellos el Director de Economía Social; y tres representantes serán designados por las Universidades vascas, uno por cada una de ellas.

\section{Funciones}

La constitución de la Confederación de Cooperativas de la Comunidad Autónoma no ha limitado, como no podía ser de otra manera, las funciones de promoción y estímulo que debe llevar a cabo el Consejo a favor del Cooperativismo vasco, por tanto no son funciones excluyentes.

Tiene facultades para difundir los principios del movimiento cooperativo, facilitar y colaborar en la investigación, planificación y ejecución de los programas de desarrollo y fomento del Cooperativismo, así como promover la educación y formación cooperativa (artículo 145.2.a). Debe también colaborar con la Administración en la difusión y cumplimiento de la Ley y sobre todo de los principios cooperativos, como así se desprende del artículo 137.1 (artículo 145.2 c); y organizar servicios de interés común para las federaciones de cooperativas y, en su caso, para estas últimas (artículo 145.2 d).

Con carácter preceptivo tiene la capacidad de informar los proyectos de disposiciones legales y reglamentarias que afecten directamente a las cooperativas o a sus organizaciones, así como realizar estu- 
dios. proposiciones y dictámenes sobre materias de su competencia (artículo 145.2 b), como son los señalados en los artículos 140.6 (Informe previo del Consejo en caso de sanciones por infracciones muy graves);141.3 a (informe para el caso de la descalificación de las cooperativas) 142.2 (informe preceptivo en caso de intervención temporal). En esta misma línea debe contribuir al perfeccionamiento legal del régimen legal e institucional del ordenamiento socioeconómico de la Comunidad Autónoma del País Vasco, participando en las instituciones y organismos existentes para su logro, como por ejemplo en el Instituto de Seguridad y Salud Laborales - OSALAN y en el Consejo Económico Social CES 34 .

Interviene además por vía de arbitraje cooperativo conforme a derecho en cuestiones litigiosas de libre disposición entre las cooperativas, entre éstas y sus socios, o entre éstos, cuando afecten primordialmente a la interpretación y aplicación de principios, normas, costumbres y usos de naturaleza cooperativa, y cuando estén obligadas por efecto de los Estatutos o así lo soliciten las partes (artículo 145.2 f); para ello se dictó el Reglamento de arbitraje del Consejo Superior de cooperativas del pleno de 9 de febrero de 198935, derogado por el Reglamento de 20 de abril de $1998^{36}$.

Finalmente, la Ley deja abiertas otras funciones del Consejo como por ejemplo las señaladas en los artículos 85.1 a) sobre la homologación de la transformación de cooperativas, o el artículo 136.6 sobre la autorización de la provisión estatutaria de repartibilidad del fondo de reserva obligatorio en las cooperativas mixtas.

En cualquier caso la función más importante que el Consejo Superior de cooperativas ha desarrollado tanto en la Ley 1/1982, como en la Ley 4/1993, a falta de un ente propiamente cooperativo que la llevara a cabo, ha sido la presencia, participación e interlocución del Cooperativismo vasco. Por lo mismo, una vez que se ha constituido la Confederación, las federaciones deben agruparse bajo la misma al ser su máximo ente representativo, hecho que inevitablemente debe afectar a la presencia de las mismas en el propio Consejo.

34 Buitrón Andrade, P., El Consejo Superior de Cooperativas de Euskadi.

35 BOPV de 11 de mayo de 1989

36 BOPV de 11 de junio de 1998. 


\section{VIII. ¿Cómo se financia?}

El Consejo goza de autonomía económico-financiera, y se financia de las cantidades asignadas en los Presupuestos generales de la Comunidad Autónoma Vasca, de las aportaciones del movimiento cooperativo, de los productos de actividades y bienes, de las cantidades provenientes de la adjudicación del haber social de las cooperativas en proceso de liquidación (artículo 94 a y d) y de cualquier otro ingreso que le sea reconocido por vía normativa sea de origen público o privado, a título oneroso o gratuito (artículo 145.5). Se someterá al régimen de Contabilidad Pública en los términos establecidos en el artículo 6.2 de la Ley 14/1994, de 30 de junio de Control Económico y Contabilidad de la Comunidad Autónoma Vasca.

DIRECCION DE ECONOMIA SOCIAL DEL GOBIERNO VASCO (ACTUACION SOBRE COOPERATIVAS Y SOCIEDADES, ANONIMAS Y LIMITADAS, LABORALES)

A la cabeza de este órgano está Alfredo IsPIzUA ${ }^{37}$, que es pues Director de Economía Social. En muy recientes intervenciones ha destacado que es necesario reactivar el espíritu promotor para crear empresas Cooperativas.

\section{Tareas que desarrolla la Dirección}

Desde el punto de vista del sujeto, la Dirección de Economía Social del Gobierno Vasco actúa sobre Cooperativas y Sociedades, anónimas y limitadas, Laborales. entre:

Objetivamente, la actividad administrativa desarrollada se reparte

— una actividad de fomento, en sentido amplio, de Cooperativas y Sociedades Laborales

37 www.euskop.org/entrev.htm: Entrevista a Alfredo Izpizua: Doctor en Derecho y Diplomado en Estudios Cooperativos, Alfredo Ispizua es, desde 1998, Director de Economía Social del Departamento de Justicia, Empleo y Seguridad Social del Gobierno Vasco y Presidente del Consejo Superior de Cooperativas de Euskadi. Profundo conocedor, pues, del movimiento cooperativista vasco. 
-y otra, de registro y control de legalidad de estos tipos societarios íntegramente en el caso de las Cooperativas y de su laboralidad en el caso de las sociedades anónimas y limitadas así calificadas.

En materia de Cooperativas la Comunidad Autónoma del País Vasco tiene competencia exclusiva y ejecuta la legislación estatal respecto de las Sociedades Laborales.

\section{I.1. Fomento}

Como actividad de fomento, compete a la Dirección la elaboración, gestión y ejecución de los programas de fomento, promoción y desarrollo de la Economía Social.

En el actual ejercicio dichas acciones se concretan en 6 Ordenes del Consejero de Justicia; Empleo y Seguridad Social, destinadas a ayudas para emprender en Economía Social, para Asistencia Técnica en las empresas de Economía Social de la CAPV, para intercooperación empresarial en la Economía Social, para la formación en Economía Social, para la participación de trabajadores en empresas y para la creación y consolidación de estructuras asociativas de las empresas de Economía Social de la CAPV.

\section{I.2. La vertiente jurídica}

Corresponde la calificación, inscripción y certificación de los actos que según la normativa vigente deban acceder al Registro de Cooperativas, la habilitación y legalización de los libros obligatorios de las Cooperativas, la recepción del depósito de las cuentas anuales de dichas entidades, la expedición de certificaciones sobre la denominación de las entidades cooperativas y la resolución de las consultas que, siendo de su competencia, le sean planteadas.

Así mismo, es competente respecto de autorizaciones para contratar trabajadores por cuenta ajena temporalmente, por encima del límite legal establecido y procedimientos de declaración de utilidad pública; como también aspectos de inspección, sanción e intervención dentro de los límites y para los supuestos legalmente previstos.

En materia de Sociedades Laborales, conoce de la calificacióndescalificación del carácter de laboral. 


\section{I.3. Dotación de recursos económicos y personales}

Si bien la dotación de los medios materiales para atender las necesidades de la Dirección puede considerarse adecuada, cabe señalar que, por lo que respecta a los medios personales, y no obstante los esfuerzos realizados hasta la actualidad para el refuerzo de dotaciones, persiste un déficit de medios personales para atender al volumen de trabajo que en la Dirección se genera.

En este sentido, se está trabajando en la actualidad en un estudio de optimización de la organización de la Dirección, para tratar de solventar dicho problema.

\section{RETOS: NUEVAS COOPERATIVAS (COMPARACION 2002-2003)}

\section{Líneas de actuación del ejercicio $\mathbf{2 0 0 2}$}

En el ejercicio de 2002 se registraron 46 cooperativas nuevas, de las que 28 son de trabajo asociado. Este modesto guarismo indica, a las claras, la necesidad de reactivar el espíritu promotor empresarial en Economía Social. En ello se comenzó a trabajar desde la Administración, dentro de su margen de maniobra en esta materia.

De cualquier forma, más allá del puro dato cuantitativo, importa analizar la condición de las empresas creadas desde la perspectiva de su potencialidad de desarrollo y creación de puestos de trabajo. Entendemos que es una prioridad clara, por lo que estamos trabajando en el diseño de la intervención administrativa posible para que efectivamente se creen este tipo de empresas; apoyando por supuesto también, la creación de cualquier empresa de Economía Social.

El emprendizaje empresarial puede deberse a causas y finalidades varias, tanto en el tiempo como geográficamente, pero aquí y ahora, está íntimamente relacionado con el empleo. Esta es una finalidad básica y principal. Y es precisamente en la Economía Social en general y en el cooperativismo en particular, donde la conexión emprendedor -empresario - trabajador se da con mayor fuerza, pues en el socio de una cooperativa de trabajo asociado concurren ambas facetas.

La intervención pública en esta materia tiene dos vertientes diferenciadas: una, de establecimiento de un entorno jurídico normativo 
que facilite la creación de empresas (aspectos sustantivos, tributarios, etc.) y otra, más proactiva, que propicie el emprender cooperativamente, lo que se ha venido denominando el fomento del espíritu empresarial en Economía Social.

Desde el primer punto de vista, ya en 2000 se modificó la Ley 4/1993, de Cooperativas de Euskadi, reduciendo de cinco a tres el número mínimo de socios para constituir una cooperativa, con reducción pareja del capital mínimo constituyente, que pasa de $1 \mathrm{M}$ de ptas. a 3.000 euros. Constatado en la práctica el reducido número de promotores por proyecto empresarial en general, se pretendía que estos pudieran optar por la fórmula cooperativa.

Pero además de ello, en el ejercicio 2002, como ya se ha dicho, se analizó, en colaboración con un equipo externo experto, nuevas formas de actuación administrativa de mayor intensidad, en cuanto a formas y resultados, para el fomento de nuevas empresas de Economía Social; añadidas a la ya tradicional línea de ayudas a la constitución de empresas de Economía Social en lo que se ha denominado Nuevos Yacimientos de Empleo, que en el presente ejercicio se ha ampliado. El objetivo era llevar a la práctica lo diseñado a partir del ejercicio 2003.

\section{Líneas de Actuación ejercicio 2003}

De cara al ejercicio 2003, era objetivo de la Dirección de Economía Social continuar con las líneas de actuación ya existentes diseñando e implantando estrategias de promoción y fomento de nuevas empresas de Economía Social, y procurando la consolidación de las ya existentes.

En este sentido, y en previsión de que en el año 2003 se produjera una prórroga de los presupuestos, la Dirección de Economía Social publicó en este ejercicio, con la intención de dar un paso más en la consecución del objetivo de fomento de la Economía Social, un programa de ayudas cuyo objetivo es la creación de nuevas empresas de Economía Social en la CAPV.

Estas empresas deberán asentarse sobre una base comarcal ya que es en este ámbito donde la experiencia ha demostrado que se aglutinan necesidades comunes capaces de aunar esfuerzos que pongan en marcha empresas de Economía Social sólidas y duraderas que es el 
objetivo fundamental de este programa. A su vez se ha constatado que el desarrollo de la Economía Social exige un liderazgo compartido con la participación tanto de la Administración Pública como de la empresa privada, empresas de Economía Social, fundaciones, escuelas profesionales, todos ellos capaces de ensayar en un nuevo contexto la creación de empresas de Economía Social, por lo que deberán involucrarse en el proyecto tanto empresas y organizaciones susceptibles de prestar cobertura a los futuros proyectos, como entidades educativas que impartan formación técnica relacionada con el mismo. Así la Administración financiará parcialmente el coste que suponga la creación de una estructura necesaria para la identificación de proyectos empresariales que cuenten con un plan de viabilidad y se concreten en la identificación de promotores capaces de desarrollar el plan de empresa y puesta en marcha de la misma.

En otro orden de ayudas, y debido a que con la entrada en vigor del Decreto 5/2000, de 24 de mayo, de medidas urgentes para la reforma del sistema de protección de desempleo y mejora de la ocupabilidad, se han modificado las condiciones para obtener la prestación por desempleo en su modalidad de pago único, se ve necesario tener en cuenta esta circunstancia y reexaminar el apoyo que desde la Administración se da a la incorporación societaria. En este sentido, se va a publicar una modificación de la Orden de ayudas para la incorporación de desempleados como socios trabajadores o de trabajo a empresas de Economía Social, generalizando un complemento a la ayuda ya existente, no sólo a los que hubieren tenido derecho a la capitalización por desempleo, sino con carácter general a todos los que realicen un desembolso al capital social de la entidad para adquirir la condición de socio trabajador de la misma.

Es de destacar que la Confederación de Cooperativas de Euskadi presentó al Departamento de Justicia, Empleo y Seguridad Social del Gobierno Vasco una propuesta de desarrollo reglamentario de la Ley de Cooperativas de Euskadi.

En cuanto a esto se ha realizado un primer estudio de la propuesta de desarrollo reglamentario de la vigente ley de cooperativas y celebrado una puesta en común, básicamente informativa, con los proponentes con objeto de precisar la causa y finalidad de cada uno de los preceptos de desarrollo que se formulan. Todo ello en aras a establecer un consenso básico sobre la necesidad y contenido reglamentario a elaborar formalmente. 


\section{Plan Estratégico 2003-2005}

Alfredo IsPIZUA, del que hemos hablado al empezar este punto, posee además el cargo de Presidente del Consejo Superior de Cooperativas de Euskadi, órgano que comentamos en este trabajo.

El Consejo Superior de Cooperativas de Euskadi, ha aprobado el Plan Estratégico para el período 2003-2005. Del análisis de la situación y los retos actuales del cooperativismo vasco ha deducido los tres Objetivos Estratégicos que van a estructurar el conjunto de acciones del CSCE-EKGK durante el próximo trienio, a saber :

-Que el modelo cooperativo sea más conocido tanto dentro de las cooperativas como en la sociedad en general.

-Que el cooperativismo sea social e institucionalmente más reconocido o apreciado, y por último

—Que se creen más cooperativas y se consoliden las existentes.

Estos Objetivos están interrelacionados, siendo el último de ellos el principal y a él se orientan de forma instrumental los dos anteriores.

En efecto, se estima que un amplio reconocimiento social de lo diferencial del sistema cooperativo, hará que éste resulte más atractivo y se crearán más empresas que opten por el modelo cooperativo; y que a su vez, el reconocimiento debe llegar por medio de un mejor conocimiento, no sólo de los fundamentos teóricos, sino de los logros producidos y de su impacto en la sociedad vasca.

Además de la concreción de estos Objetivos, el Plan Estratégico define las estrategias para alcanzar los mismos así como las actuaciones que traducen, de forma operativa, lo que el Consejo va a hacer o promover para tal fin; siendo las más destacables las orientadas a potenciar los instrumentos de apoyo, asesoramiento y fomento cooperativos, así como al establecimiento de programas de fomento y de apoyo a la intercooperación estructural.

En opinión de IsPIZUA en cuanto a las principales fortalezas del cooperativismo como forma societaria para hacer empresa expone lo siguiente:

En una sociedad y economía como las actuales, que se caracterizan como "del conocimiento» al igual que el trabajador, éste adquiere una importancia creciente, si no decisiva, en éxito de los proyectos empresariales, de forma que se buscan métodos diversos que propicien su formación, motivación, responsabilidad y participación 
en aquel proyecto, que se presenta y oferta muchas veces, como «común». Esta participación exige, en su desarrollo y consecuencias propias, no sólo participar en su ejecución, sino también en su gestión y resultados; de forma que se aúna y vincula el desarrollo personal y el empresarial. Ese vínculo genera un sentimiento y, con el tiempo, una realidad de pertenencia y en última instancia, un resultado de permanencia en el lugar al que pertenecen los partícipes, con independencia de la necesaria expansión del negocio.

En esto radica, precisamente, lo esencial del cooperativismo. En esto y en cierto grado, eficaz, de solidaridad, entendida como mutua ayuda, individual y colectiva. Todos ellos son factores internos, estimo que de fortaleza, de la empresa cooperativa.

\section{CONCLUSION: COOPERATIVISMO CON FUTURO Y DE FUTURO}

Cabría predecir una evolución cada vez mayor de este sector económico. Así puede constatarse su tendencia evolutiva del estudio comparado del sexenio 1994-2000 de las Cuentas de la Economía Social se desprende sintéticamente:

- Un incremento constante de empleo todos los años (12.400 empleos en todo el período), de forma que su peso relativo en la economía vasca pasa de 5,8\% en 1994 a 6,5\% en 2000. Significativamente, la mujer se ha incorporado decisivamente a las empresas de Economía Social vascas: pasa de representar el 29,4\% del empleo en 1996 al 35,6\% en 2000. Un incremento del Valor Añadido Generado, cuyo peso relativo pasa de 5,0\% al principio del período a 5,6\% al final del mismo.

- Incremento de competitividad, en tanto que la productividad aparente por empleado en términos reales pasa de 4,7 a 5,3\% M. de ptas., aún cuando se ha ralentizado en el último bienio.

- Progresiva diversificación del tejido industrial, con terciarización creciente respecto de las nuevas actividades emprendidas.

- Creciente apertura a mercados exteriores, con incremento constante de la exportación, que en el sector industrial pasa del $30,6 \%$ de ventas al 38,4\%; lo que ocasiona una mayor dependencia de los mercados internacionales.

- Crecimiento significativo de Recursos Propios de manera que se han consolidado gradualmente la solvencia económica y financiera agregados de la Economía Social, lo que ha permitido una 
importante reinversión de excedentes en activos materiales e inmateriales (incremento del $43 \%$ ).

La tendencia como indicador de la evolución de un fenómeno en un período prolongado, permite inducir su sentido en el futuro al menos, próximo y en condiciones normales.

Así, las variables citadas dan cuenta sin duda, de la solidez de las bases esenciales de las empresas cooperativas vascas.

Si se consolidan las nuevas iniciativas empresariales y no se descuidan los aspectos específicamente cooperativos singularmente, la formación Cooperativa continua y el esfuerzo creciente en la cooperativización del trabajo prestado en una cooperativa, parece prudente y razonable concluir que el cooperativismo vasco, en su conjunto, es un cooperativismo con futuro y de futuro.

\section{BIBLIOGRAFIA}

Divar, J.: La metamorfosis del capital, bases de la empresa. Ed. Publicaciones de la Universidad de Deusto, Bilbao, 1983.

Divar, J.: Una alternativa ante la crisis. Ed. Ceac, Barcelona, 1985.

GADEA, E.: Derecho de las Cooperativas (Análisis de la Ley 4/1993 de 24 de Junio, de Cooperativas del País Vasco). Ed. Publicaciones de la Universidad de Deusto, Bilbao, 2001.

-Evolución de la legislación cooperativa en España. Ed. Consejo Superior de Cooperativas de Euskadi, Vitoria, 1999. 